\title{
Optimal Design of Internal Capital Markets*
}

\author{
Andrey Malenko \\ Graduate School of Business, Stanford University
}

February 2011

\begin{abstract}
This paper studies optimal design of a capital allocation system in a firm in which the division manager with empire-building preferences privately observes the arrival and properties of investment projects, and the headquarters is able to audit each project at a cost. Under certain conditions, the optimal system takes the form of a budgeting mechanism with threshold division of authority. Specifically, the headquarters: (i) allocates a spending account to the manager at the initial date and accumulates it over time; (ii) sets a threshold on the size of individual projects, such that all projects below the threshold are delegated to the manager and financed out of her spending account, while all projects above the threshold are audited and financed fully by the headquarters. The model is extended in several directions, including multiple audit technologies, multiple project categories, and the possibility of renegotiation.
\end{abstract}

*I thank my dissertation committee: Steven Grenadier, Peter DeMarzo, and Jeffrey Zwiebel for many insightful comments and guidance. I am also grateful to Nicholas Bloom, Darrell Duffie, Dirk Jenter, Arthur Korteweg, Ilan Kremer, Nadya Malenko, Ian Martin, Holger Mueller, Gaizka Ormazabal, Michael Ostrovsky, Lasse Pedersen, Francisco Pérez-González, Paul Pfleiderer, Stefan Reichelstein, Andrzej Skrzypacz, Ilya Strebulaev, and seminar participants at New Economic School, New York University, Stanford University, and the University of Houston for helpful comments and discussions. I am responsible for all remaining errors. Address for correspondence: Graduate School of Business, Stanford University, 518 Memorial Way, Stanford, CA 94305; email: amalenko@stanford.edu. 


\section{Introduction}

Investment activity is fundamental to any corporation. Investment decisions not only determine success of a single firm but also are important for society as a whole through their effect on economic growth. While some investment occurs in small firms operated by single owner-managers, a substantial portion of investment is made by large corporations, which continuously execute a large number of investment projects. These corporations typically have a hierarchical structure, leading to internal frictions. Investment projects are often conceived on lower levels of the organization, whose managers are likely to have different incentives from upper-level managers, let alone shareholders. ${ }^{1}$ To address these concerns, corporations design capital allocation systems that specify how investment decisions are made.

While corporations are heterogeneous in how they organize investment activity, there are two features of organizational practices that are common. The first feature is the use of spending accounts, or budgets. ${ }^{2}$ Specifically, the upper-level management (e.g., the headquarters) assigns a spending account to a lower-level manager (e.g., the division manager). The manager is often given considerable discretion how to spend her account across projects and over time. Importantly, the spending account makes investment decisions interconnected: investing more in a project today reduces the remaining allocation for projects tomorrow. The second widespread feature is threshold division of authority. Specifically, the upper-level management limits the manager's discretion by imposing a threshold on the size of individual projects, such that all investment projects with size below the threshold are delegated to the manager, while all investment projects with size above the threshold are passed to the upper-level management. ${ }^{3}$

Despite the widespread use of spending accounts, prior attempts to formally study optimal design of capital allocation systems are almost uniformly limited to static models. ${ }^{4}$ Because spending accounts are dynamic by their nature, to understand whether they are efficient from an organizational point of view, it is important to study the design of capital allocation systems in a dynamic setting. In this paper, I analyze this issue by asking the following

\footnotetext{
${ }^{1}$ For example, according to survey evidence in Petty, Scott and Bird (1975), the majority of respondents ("Fortune 500" firms) indicated that less than $20 \%$ of investment projects are originated at the central office level. Akalu (2003) provides similar evidence for European firms based on more recent data. See Ross (1986) for evidence that large manufacturers continuously deal with a very large number of investment projects.

${ }^{2}$ Gitman and Forrester (1977), Ryan and Ryan (2002), and Akalu (2003) present survey evidence that central offices at many firms assign capital budgets to lower levels such as divisions.

${ }^{3}$ For survey evidence, see, e.g., Gitman and Forrester (1977), Ross (1986), Slagmulder, Bruggeman, and van Wassenhove (1995), Ryan and Ryan (2002), and Akalu (2003).

${ }^{4}$ See the end of this section for a review of the literature.
} 
normative question. What is the best possible way to organize investment activity between the headquarters and the division manager in a dynamic context, if investment projects are conceived at the division level, the headquarters observes neither their origination nor properties unless it spends a cost, and the division manager has empire-building preferences? My main result is that under certain conditions, despite allowing for all possible ways to organize investment activity, the optimal mechanism takes a very simple form, which incorporates both features mentioned above. The headquarters allocates a spending account to the manager, accumulates it over time, and specifies a threshold on the size of individual projects that separates authority between the parties.

More specifically, I consider a continuous-time principal-agent environment in which a risk-neutral principal (the headquarters) employs a risk-neutral agent (the division manager). In practice, investment projects are typically originated on lower levels of corporations and project origination is continuous (e.g., Akalu (2003)). To account for this, I assume that the firm has access to a sequence of investment opportunities that arrive stochastically over time and whose arrival is observed only by the division manager. To capture heterogeneity of investment projects, I assume that each investment project is characterized by a quality parameter learned by the division manager upon its arrival. The quality of the project determines the optimal amount of investment. The agency problem stems from the fact that the headquarters and the division manager have different preferences with respect to investment. While the headquarters operates in the interests of shareholders, the division manager not only enjoys utility from monetary compensation but also gets an "empire-building" private benefit from each dollar of investment. Thus, from the position of the headquarters there is a concern that if the division manager wants to invest a lot in a project, it can be a result of her empire-building preference rather than the fundamentals of the project. At any time the headquarters can use two tools to provide the division manager with appropriate incentives. First, it can punish the division manager for high spending today by being tougher in the future. Second, it can audit the division manager at a cost and find out the quality of the current project with certainty. The goal is to find a mechanism that maximizes the discounted value of the firm subject to delivering the division manager the expected utility of at least a given amount.

I show that a simple mechanism, called a budgeting mechanism with threshold division of authority, is optimal in this setting. In this mechanism, the headquarters allocates a spending account to the division manager at the initial date and accumulates it over time at a certain rate. The division manager is allowed to finance investment projects out of her 
account at her own discretion. In addition, the headquarters specifies a threshold on the size of individual projects, such that at any time the division manager has an option to pass the project to the headquarters claiming that it deserves investment above the threshold. Upon the receipt of the project, the headquarters audits it. If the audit confirms that the project indeed deserves an investment above the threshold, the project gets financed fully by the headquarters. Otherwise, the division manager is punished. In equilibrium, the division manager passes a project to the headquarters if and only if it indeed deserves investment above the specified threshold. Thus, this arrangement divides authority between the division manager and the headquarters. All small investment decisions are made at the division level and are financed out of the division manager's spending account. In contrast, all large projects are passed to the headquarters, even though they are originated at the division level. They get approved and financed fully by the headquarters.

The intuition for optimality of this arrangement is as follows. To provide incentives not to overinvest, the headquarters must either audit the project or punish the division manager in the future for high investment today. If auditing is too costly, the second tool is optimal and can be implemented via a spending account. Intuitively, because the spending account balance decreases by the amount of investment, the division manager's expected future utility decreases by the amount of private benefits from the current investment opportunity. As a consequence, the division manager finds it optimal to allocate her spending account between the current and future investment opportunities in the way that maximizes firm value. As the spending account accumulates over time and gets drawn on to finance investment projects, it acts as a "memory device," tracking changes in the division manager's future expected utility. This role is similar to the role of a credit line in DeMarzo and Fishman (2007b) and DeMarzo and Sannikov (2006).

The incentive role of a spending account comes at a cost. Higher investment out of the spending account decreases the remaining allocation for future projects and thus constrains future investment activity. If the size of the current project is large enough, the increase in financing constraints becomes more costly than the audit. Consequently, there exists a threshold on the size of individual projects such that it is optimal to provide incentives through the audit if the size of the project exceeds this threshold. Because distortions in the spending account are costly, it is optimal to finance all projects audited by the headquarters without using the spending account of the division manager. This outcome can be implemented through giving the division manager an option to pass the project to the headquarters claiming that it deserves an investment above the threshold. Because the division manager 
obtains free financing from the headquarters, she has incentives to pass the project to the headquarters if the optimal investment indeed exceeds the threshold. However, because of expected punishment, she has no incentives to pass the project to the headquarters if the optimal investment is below the threshold.

While the use of capital budgets augmented by thresholds on the size of individual projects is common, sometimes corporations use other arrangements. For example, some firms do not impose a threshold on the size of individual projects and instead give division managers complete authority to spend the allocated amount over time and over projects (Slagmulder, Bruggeman, and van Wassenhove (1995)). This arrangement corresponds to the optimal mechanism in this paper if the cost of audit is infinite. In this case, the only tool that the headquarters can use to provide the division manager with incentives not to overinvest is punishing her in the future for high investment today. Thus, assigning a rigid spending account and giving the division manager complete authority is optimal. Another arrangement that firms sometimes use is requirement of approval from corporate headquarters for all investments. This arrangement corresponds to the optimal mechanism in this paper if the cost of audit is zero. In this case, the headquarters finds it optimal to audit all investment projects. The optimal outcome can be equivalently implemented by requiring the division manager to get approval for all investments and approving them only if they are value-maximizing. ${ }^{5}$

The optimal mechanism in this paper implies several properties of corporate investment that may seem suboptimal at first glance. First, either overinvestment or underinvestment relative to the zero-NPV rule can occur depending on the prior history. If there have been many investment projects financed by the division manager in the recent past, then the division manager's spending account balance is low, leading to underinvestment relative to the zero-NPV rule. By contrast, if there have been few investment projects financed by the division manager in the recent past, then the division manager's spending account balance is high, leading to overinvestment relative to the zero-NPV rule. Second, under the optimal mechanism, other things equal, investment projects financed by the division are treated more "harshly" than investment projects financed by the headquarters: conditional on the same quality of an investment project, the size of investment is higher if it is financed by the headquarters. This property arises in the model because projects financed out of the division manager's spending account are subject to higher financing constraints. It is consistent with

\footnotetext{
${ }^{5}$ This result seems to be consistent with anecdotal evidence. For example, the sample in Bloom et al. (2010) contains a textile plant in India, in which the plant manager is required to get an approval from his supervisor, the division manager, for all spending decisions, even the very minor ones. Interestingly, the division manager lives in a building next to the plant, which is likely to imply a very low cost of audit.
} 
survey evidence: for example, Ross (1986) finds that divisions use higher discount rates than corporate investment committees when approving investment projects.

Optimality of the budgeting mechanism with threshold division of authority hinges on two important assumptions. The first assumption is that private benefits that the division manager gets from investing a given amount are the same across all projects. This might be a good approximation if all projects belong to the same category, but it is likely to be violated if the division manager deals with very heterogeneous projects. The second assumption is the absence of performance-based compensation of the division manager. Thus, my model suggests that the budgeting mechanism with threshold division of authority is not "one solution for all." Instead, it is optimal only in settings, in which managers deal with relatively homogeneous projects and the use of performance-based compensation is limited, e.g., because of high costs of it or imperfect observability of realized values.

To explore how the optimal mechanism is affected by relaxation of these two, as well as several other assumptions, I consider a number of extensions of the model. To relax the first assumption, I consider a setting with two categories of investment projects with different levels of private benefits. I argue that this feature may give rise to the use of multiple spending accounts, one for each category of investment projects. This might explain why corporations often use separate budgets for different kinds of activities: for example, a separate budget for R\&D and a separate budget for capital investment. To see how my results are affected by allowing for performance-based compensation, I discuss what happens if the division manager cares about firm value in addition to her preferences in the base setting. Even though the budgeting mechanism with threshold division of authority is no longer optimal, I argue that it is still a natural mechanism if the headquarters is uncertain to what extent the division manager cares about firm value.

While the main model has a single threshold that separates authority between the headquarters and the division manager, in practice corporations often impose multiple thresholds that divide authority between different levels of the corporate hierarchy. For example, Ross (1986) shows that in a typical large manufacturing corporation, the division manager makes decisions on small projects on her own, while passing larger projects to the corporate investment committee and the largest projects to the CEO. I show that multiple thresholds on the size of individual projects naturally arise in an extension of the model that allows for multiple audit technologies. Specifically, I consider a setting with two audit technologies, in which technology 1 is less efficient but also cheaper than technology 2. If technologies 1 and 2 are interpreted as audit by the corporate investment committee and by the CEO, respec- 
tively, then the optimal mechanism implies two thresholds that separate authority between the division manager, the corporate investment committee, and the CEO.

In the fourth extension, I allow for renegotiation between the parties and solve for an optimal renegotiation-proof mechanism. ${ }^{6}$ I show that the budgeting mechanism with threshold division of authority is again optimal, albeit with different parameters. Other things equal, the size of the division manager's spending account in the optimal renegotiation-proof mechanism is lower than that in the optimal mechanism, which provides an implication that the size of the spending account increases in the commitment power of the parties. Finally, I consider a finite-horizon analogue of the model and show that the optimal mechanism in the finitehorizon model is a natural analogue of the optimal mechanism in the base model. The finite-horizon model allows me to examine the optimality of the "use-it-or-lose-it" feature of many real-world budgeting arrangements. While it is not optimal in my model, I argue that it is a natural choice if the headquarters is uncertain about the private benefits that the division manager obtains from investment.

The rest of the paper is organized as follows. The remainder of this section discusses the relation of this paper to the existing literature. Section 2 describes the setup of the model and formulates the problem of optimal organization of investment activity. Section 3 applies the revelation principle and solves for the optimal direct mechanism. Section 4 shows how policies implied by the optimal direct mechanism can be equivalently implemented using the budgeting mechanism with threshold division of authority. Section 5 discusses the relation of the optimal mechanism in the paper to observed mechanisms and derives implications for investment. Section 6 provides extensions of the model. Finally, Section 7 concludes. The proofs of all lemmas and propositions are provided in the appendix.

\section{Relation to the Literature}

This paper is related to several strands of literature. First, it belongs to the literature on investment appraisal in the presence of intra-firm information and agency frictions. This literature was started by Harris, Kriebel, and Raviv (1982) and Antle and Eppen (1985), who focus on the role of transfer pricing in allocating resources within the firm. Because my focus is on audit by the headquarters, my paper is most closely related to Harris and Raviv (1996, 1998). Harris and Raviv (1996) consider a one-shot interaction between the headquarters

\footnotetext{
${ }^{6}$ I allow for renegotiation with respect to the size of the spending account but keep the assumption that the headquarters is able to commit to audit strategies.
} 
and the division manager, in which the division manager has private information about the project and the headquarters may audit it at a cost. They show that the optimal mechanism consists of an initial spending limit that the division manager can request to increase under the threat of getting audited by the headquarters. Harris and Raviv (1998) extend their earlier paper to the case of two investment projects and show that the same solution applies, with the difference that the initial spending limit is allocated for both projects. This paper considers the dynamic version of the problem. Unlike in a one-shot case, where audit is the only way to provide incentives not to overspend, in a repeated setting the headquarters has an additional tool of incentive provision. Specifically, it can provide incentives dynamically by punishing (rewarding) the manager for high (low) past spending. My paper studies the interaction between these two tools of providing incentives. It shows that the long-term spending account implements the second, dynamic, tool of incentive provision. Interestingly, the optimal mechanism involves the use of the first tool, audit, even if the account balance is more than enough to cover the project's investment cost. ${ }^{7}$ The budgeting feature makes my paper related to Mookherjee and Reichelstein (1997), who also argue that a budgeting mechanism is optimal, albeit in a very different setting. ${ }^{8}$ Holmstrom and Ricart i Costa (1986), Bernardo, Cai, and Luo (2001, 2004), and Bernardo, Luo, and Wang (2006) study the interplay between capital allocation and performance-based compensation. My study is different from these papers in its focus on settings in which performance-based compensation is not feasible (e.g., due to projects' long horizon or externalities among divisions).

The paper also belongs to the literature on optimal dynamic contracting that uses recursive techniques to characterize the optimal contract. These techniques were developed by Green (1987), Spear and Srivastava (1987), and Thomas and Worrall (1988) for discrete-time models and were later extended by Sannikov (2008) and DeMarzo and Sannikov (2006) for settings in continuous time. Within this literature, my work is most closely related to two types of papers. First, it is related to models with risk-neutral agents that are based on repeated hidden information. ${ }^{9}$ The role of the spending account in my model is similar to the role of a

\footnotetext{
${ }^{7}$ In Section 6, Harris and Raviv (1998) consider an extension in which two projects are sequential. In their setting, the headquarters punishes the division manager for spending too much in the first project by assigning a lower allocation of capital for the second project. However, this extension assumes that audit is not feasible, and thus there is no interaction between the two tools of incentive provision.

${ }^{8}$ Specifically, Mookherjee and Reichelstein (1997) consider a static model of a hierarchical organization, in which each agent receives a task and a budget from a supervisor and assigns tasks and budgets to her subordinates, who, in turn, do the same for their subordinates, etc.

${ }^{9}$ DeMarzo and Sannikov (2006), Biais et al. (2007), DeMarzo and Fishman (2007b), Tchistyi (2006), Piskorski and Tchistyi (2010).
} 
credit line in DeMarzo and Fishman (2007b) and DeMarzo and Sannikov (2006): it acts as a "memory device," tracking all relevant prior history. My paper contributes to this literature by incorporating the costly state verification framework into the dynamic principal-agent setting and solving the problem in this setting. Second, because the budgeting mechanism introduces financing constraints on the division manager, my paper is related to the literature that studies corporate investment in the presence of history-dependent financing constraints. ${ }^{10}$ This literature considers financing constraints between the firm and the outside investors. In contrast, in my model, the firm itself is not financially constrained, but imposes constraints on the division manager to address agency problems inside the firm.

Finally, threshold division of authority in the optimal mechanism in my paper relates it to the literature on optimal delegation. ${ }^{11}$ This literature studies when it is optimal to delegate a decision to an expert, who is better informed but biased. The optimal delegation in this literature often takes the form of a threshold. Because of a deeper focus on issues related to delegation, prior studies in this literature do not allow for budgeting mechanisms. In addition, they often restrict the set of admissible mechanisms ex-ante. As a consequence, optimal mechanisms in these papers are often not globally optimal. In contrast, in my model, threshold division of authority is part of a globally optimal mechanism.

\section{The Model}

In this section, I describe the setup of the model and formulate the general mechanism design problem, which is analyzed in subsequent sections.

\subsection{The Environment}

The setup of the model extends the one-period principal-agent framework that is similar to Harris and Raviv (1996) to a dynamic environment, in which the principal and the agent interact repeatedly and investment opportunities arrive randomly over time. I consider a corporation that consists of two parties: the principal ("the headquarters") and the agent ("the division manager"). The headquarters is risk-neutral and operates in the interest of the firm's shareholders. The division manager is risk-neutral and operates in her own private

\footnotetext{
${ }^{10}$ Albuquerque and Hopenhayn (2004), Quadrini (2004), Clementi and Hopenhayn (2006), DeMarzo and Fishman (2007a), DeMarzo et al. (2009).

${ }^{11}$ Dessein (2002), Harris and Raviv (2005), Marino and Matsusaka (2005), Alonso and Matouschek (2007, 2008).
} 
interest. The corporation is characterized by a sequence of investment opportunities that arrive randomly over time, whose arrival and quality are observable only by the division manager. Since the focus of the paper is on internal capital markets, I assume that the headquarters is the only source of capital for investment. ${ }^{12}$

Time is continuous, indexed by $t \geq 0$, and the horizon is infinite. ${ }^{13}$ The discount rates of the headquarters and the division manager are equal to $r>0$ and $\rho>r$, respectively. ${ }^{14}$ Over each infinitesimal period of time $[t, t+d t]$, the division gets a new investment project with probability $\lambda d t$. Each project is characterized by a quality parameter $\theta$, which is an i.i.d. draw from a distribution with c.d.f. $F(\theta)$ and p.d.f. $f(\theta)$ defined over $\Theta=[\underline{\theta}, \bar{\theta}]$, where $\bar{\theta}>\underline{\theta}>0$. Formally, the occurrence of investment projects is an independently marked homogeneous point process $\left(\left(T_{n}, \theta_{n}\right)\right)_{n \geq 1}$, where $T_{n}$ and $\theta_{n}$ denote the arrival time and the quality of the $n^{\text {th }}$ investment project. ${ }^{15}$ Indeed, $\left(T_{n}\right)_{n \geq 1}$ is a homogeneous Poisson process with intensity $\lambda$, and $\left(\theta_{n}\right)_{n \geq 1}$ is an i.i.d.-sequence of random elements independent of $\left(T_{n}\right)$.

Each investment project is a take-it-or-leave-it opportunity that generates the net present value (NPV) of $V(k, \theta)-k$, where $V(k, \theta)$ is the present value from the project as a function of the amount $k \geq 0$ of capital invested and the quality of the project $\theta$. The function $V(\theta, k)$ is assumed to satisfy the following set of technical restrictions:

Assumption 1. The present value of investing $k$ in a project with quality $\theta, V(k, \theta)$, has the following properties:

(a) $V(0, \theta)=0$;

(b) $\frac{\partial^{2} V(k, \theta)}{\partial k^{2}}<0, \lim _{k \rightarrow 0} \frac{\partial V(k, \theta)}{\partial k}=\infty$, and $\lim _{k \rightarrow \infty} \frac{\partial V(k, \theta)}{\partial k}=0$;

(c) $\frac{\partial V(k, \theta)}{\partial k \partial \theta}>0$.

The technical restrictions specified in Assumption 1 are natural. Part (a) of the assumption means that the project generates zero value if there is no investment, i.e., if the investment

\footnotetext{
${ }^{12}$ The paper does not address the question of optimal boundaries of the firm. For models that study the choice between stand-alone and integrated firms based on costs and benefits of internal capital markets, see, e.g., Gertner, Scharfstein, and Stein (1994), Matsusaka and Nanda (2002), Inderst and Müller (2003), and Mathews and Robinson (2008).

${ }^{13}$ The assumption of infinite horizon is made to preserve stationarity of the model. However, it is not critical for the results. See Section 6.5 for the finite-horizon analogue of the model.

${ }^{14}$ The assumption that $\rho>r$ guarantees that it is not optimal to delay compensating the division manager for an infinitely long period of time. It is intuitive: for example, $\rho$ can exceed $r$ because it reflects a probability of the division manager leaving the firm. In Section 6.5 I consider a finite-horizon model under the assumption that $\rho=r$.

${ }^{15}$ See Last and Brandt (1995) for definitions of concepts in the theory of marked point processes.
} 
opportunity is passed by. Part (b) means that each project exhibits decreasing returns to scale, which range from infinity for the first dollar invested to zero for the infinite dollar invested. This assumption ensures that there will always be a positive and finite investment in each project. In particular, it implies that for any $\theta$ there exists a unique level of investment $k^{0}(\theta)$ that maximizes the net present value of the project. It is given implicitly by

$$
\frac{\partial V\left(k^{0}(\theta), \theta\right)}{\partial k}-1=0
$$

which simply states that at $k^{0}(\theta)$ the net present value from a marginal unit of investment is equal to zero. Throughout the paper, I call $k^{0}(\theta)$ the NPV-maximizing level of investment. Finally, part (c) states that the marginal product of capital is higher if the quality of the project is higher. Intuitively, this means that a higher-quality project is uniformly better. Consequently, $k^{0}(\theta)$ is a strictly increasing function of $\theta$. For convenience, I define $V(k, 0)=0$ to be the present value of investing $k \geq 0$ when there is no project available.

Let $\left(d X_{t}\right)_{t \geq 0}$ denote the stochastic process describing the evolution of the division's investment opportunities. Specifically, let $d X_{t}=0$ if there is no arrival of the project at time $t$ and $d X_{t}=\theta$ if an investment project of quality $\theta$ arrives at time $t$. The division manager has informational advantage over the headquarters in that the arrival of each project and its quality (i.e., $d X_{t}$ ) are privately observed by the division manager. The headquarters can learn about the arrival and quality of projects from two sources. First, it can rely on the reports of the division manager. Second, at any time $t$, the headquarters can independently investigate (audit) the division and learn the value of $d X_{t}$ with certainty. The fact that audit reveals $d X_{t}$ as opposed to the whole history of $X_{t}$ allows to interpret audit as investigation of prospects of a single investment project. Following other models of costly state verification, ${ }^{16}$ I assume that when the headquarters audits the division, it incurs a cost $c>0$. One interpretation of this cost is the time and effort that the headquarters needs to spend to examine the true properties of the project. ${ }^{17}$ Let $\left(d A_{t}\right)_{t \geq 0}$ be the stochastic process describing the audit decisions of the headquarters: for any $t, d A_{t}=1$ if the headquarters audits $d X_{t}$, and $d A_{t}=0$, otherwise. I do not allow for random audit strategies for the most of the paper, but relax this assumption somewhat in Section 6.1.

\footnotetext{
${ }^{16}$ For early models of costly state verification, see Townsend (1979) and Gale and Hellwig (1985).

${ }^{17}$ In practice, a subordinate is often able to hide an investment project from her supervisor, in case she wants to (e.g., see Berkovitch and Israel (2004) for a discussion). While this ability is not captured in the model, it has no effects on the results, because under the optimal mechanism in the model the division manager will never want to hide projects.
} 
To complete the setup of the model, it remains to define the preferences of the headquarters and the division manager. In addition to investment and audit decisions, I allow for monetary transfers from the headquarters to the division manager. The utility of the headquarters from a non-negative stream of investment $\left(d K_{t}\right)_{t \geq 0}$, non-negative stream of monetary compensation $\left(d C_{t}\right)_{t \geq 0}$ of the division manager, and audit decisions $\left(d A_{t}\right)_{t \geq 0}$ coincides with those of shareholders and is given by

$$
\int_{0}^{\infty} e^{-r t}\left(V\left(d K_{t}, d X_{t}\right) d N_{t}-d K_{t}-d C_{t}-c d A_{t}\right)
$$

where $\left(d N_{t}\right)_{t \geq 0}$ denotes the process of arrival of investment projects: $d N_{t}=1$, if $t=T_{n}$, and $d N_{t}=0$, otherwise. When there is no conflict of interest between the division manager and the headquarters, the problem is trivial: the first-best solution can be achieved if the headquarters simply asks the division manager to invest $k^{0}(\theta)$ when a project of quality $\theta$ arrives. It is therefore worthwhile to focus on the case in which the division manager and the headquarters have conflicting preferences with respect to investment decisions. Following prior literature that studies investment inside firms, ${ }^{18} \mathrm{I}$ assume that the division manager derives utility both from monetary compensation (the "monetary" component) and from investment activity (the "empire-building" component). More specifically, an investment of $d K_{t}$ at time $t$ increases the manager's utility at time $t$ by $\gamma d K_{t}$, where $\gamma \in(0,1)$. Thus, the utility of the division manager from streams of investment $\left(d K_{t}\right)_{t \geq 0}$ and monetary compensation $\left(d C_{t}\right)_{t \geq 0}$ is equal to

$$
\int_{0}^{\infty} e^{-\rho t}\left(\gamma d K_{t}+d C_{t}\right)
$$

This form of preferences represents the dynamic extension of the division manager's preferences in Berkovitch and Israel (2004). ${ }^{19}$ The preference for higher investment may reflect perquisite consumption associated with running larger projects as well as an intrinsic preference for empire-building. Perhaps, the simplest foundation for (3) is the "stealing" argument: out of each dollar of investment, the manager "steals" $\gamma \in(0,1)$ dollars for personal consumption and spends the remaining $1-\gamma$ dollars on productive investment activity. ${ }^{20}$ Coefficient

\footnotetext{
${ }^{18}$ E.g., Harris and Raviv (1996, 1998) and Berkovitch and Israel (2004). See Stein (2003) for a review.

${ }^{19}$ The assumption that the utility from investment accrues only at the time of investment is without loss of generality. An equivalent assumption is that $\gamma d K_{t}$ is the present value of all future private benefits from an investment of $d K_{t}$ at time $t$. For example, if an investment of $d K_{t}$ leads to a flow of private benefits of $\tilde{\gamma} d K_{t}$ for any time $s \geq t$, then the corresponding present value of private benefits if $(\tilde{\gamma} / \rho) d K_{t}$. This setting is equivalent to $(3)$ with $\gamma=\tilde{\gamma} / \rho$.

${ }^{20}$ Note that the "stealing" argument implies that the project's present value is affected by $\gamma$. In this case, one can equivalently define the effective project's present value as $\hat{V}(\theta, k)=V(\theta,(1-\gamma) k)$. Here, $k$ and
} 
$\gamma$ captures the relative importance of empire-building for the division manager.

The setup of the model has two properties that will be important for optimality of the budgeting mechanism with threshold division of authority. The first property is the absence of performance-based compensation of the division manager. It arises in the model because signals about a project's quality occur only prior to the investment and the division manager's utility (3) does not explicitly depend on the project values. One can view organization of investment procedures and performance-based compensation of division managers as two alternative tools that help the headquarters solve the same agency and information problems inside the firm. For example, in the extreme case in which the division manager owns the firm, organization of investment procedures is redundant. Because the main model rules out performance-based compensation, it applies to contexts in which the use of performancebased compensation of division managers is limited. This is the case in many corporations, likely because performance-based compensation is expensive, as in the case when each division constitutes only a small part of the corporation, or because the realized values from investment projects are not easily observed, as in cases of long-term projects and projects with externalities among divisions. In Section 6.3 I consider an extension that relaxes this assumption.

The second property is that investment of the same amount in any project generates the same private benefits to the division manager: $\gamma$ is constant for all projects. This assumption is reasonable if all investment projects belong to the same category (e.g., advertising) but is likely to be violated if projects are very heterogeneous: for example, the division manager is likely to obtain higher private benefits from spending a dollar on renovation of her office than on a marketing campaign. In Section 6.2 I consider an extension that allows for multiple categories of projects with different levels of private benefits. I argue that this feature leads to the use of multiple spending accounts with a separate account for each category of projects.

Because my goal is to study optimal organization of investment activity, for the most of the paper I assume that the parties are able to commit to any long-term mechanism. I partly relax the commitment assumption in Section 6.4. Finally, I assume that the headquarters has all bargaining power subject to delivering the division manager the time-0 utility of at least $R$. Varying $R$ allows to see how the solution is affected by the division of bargaining power between the headquarters and the division manager.

$(1-\gamma) k$ are the pre-stealing and the post-stealing levels of investment, respectively. It is easy to see that $\hat{V}(\theta, k)$ satisfies conditions in Assumption 1 as long as $V(\theta, k)$ satisfies them. 


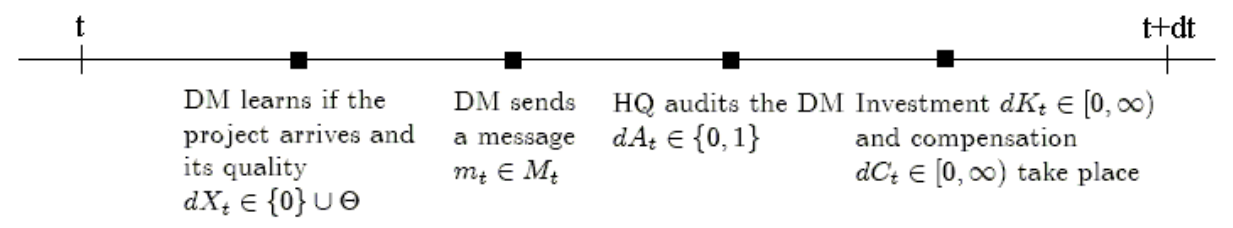

Figure 1. Timeline of the communication game.

\subsection{Formulation of the Mechanism Design Problem}

The mechanism design problem is to find a mechanism that maximizes the time- 0 expected utility of the headquarters subject to delivering the division manager the time- 0 expected utility of at least $R$. To consider the widest possible set of mechanisms, I start with a general communication game with arbitrary message spaces and complete history-dependence. At any time $t \geq 0$, the sequence of events over the infinitesimal time interval $[t, t+d t]$ is as follows. At the beginning of each period the division manager learns $d X_{t}$ : whether the project arrives and, if the project arrives, its quality. Then, the division manager sends a message $m_{t}$ from message space $M_{t}$. Given message $m_{t}$ and the history of prior messages and audits, the mechanism reacts by prescribing the headquarters to audit the division manager $\left(d A_{t}=1\right)$ or not $\left(d A_{t}=0\right)$. Finally, given message $m_{t}$, the result of the audit (if there was audit), and the history of prior messages and audits, the mechanism prescribes the level of investment $d K_{t} \geq 0$ and compensation $d C_{t} \geq 0$. The sequence of events is shown on Figure 1.

By the revelation principle, any outcome that can be implemented with a general mechanism can also be implemented with a truth-telling direct mechanism. Thus, in the search for an optimal mechanism, I can restrict attention to the class of truth-telling direct mechanisms. In other words, it is sufficient to focus only on mechanisms in which at any time $t$ the division manager sends a report $d \hat{X}_{t} \in\{0\} \cup \Theta$, saying whether the project is available and, if it is available, what its quality is, and in which the division manager finds it optimal to always send truthful reports $d \hat{X}_{t}=d X_{t}$. Given this, my analysis proceeds in the following way. In Section 3 I optimize over the set of truth-telling direct mechanisms. Because the optimal truth-telling direct mechanism is optimal among all possible mechanisms, it must be the case that any optimal mechanism implements the same audit, investment, and compensation 
policies as the optimal truth-telling direct mechanism. Hence, establishing in Section 4 that the budgeting mechanism with threshold division of authority implements the same audit, investment, and compensation policies as the optimal truth-telling direct mechanism allows me to conclude that it is optimal.

The problem of optimal design of a truth-telling direct mechanism can be formalized in the following way. The reporting strategy $\hat{X}=\left\{d \hat{X}_{t} \in\{0\} \cup \Theta\right\}_{t \geq 0}$ is an $\mathcal{F}$-adapted stochastic process, where $\mathcal{F}=\left\{\mathcal{F}_{t}\right\}_{t \geq 0}$ is the filtration generated by $\left(\left(T_{n}, \theta_{n}\right)\right)_{n \geq 1}$. The direct mechanism $\Gamma$ is described by a triple $(A, K, C)$ of stochastic processes such that the audit process $A=$ $\left\{d A_{t} \in\{0,1\}\right\}_{t \geq 0}$ is measurable with respect to $\left\{d \hat{X}_{s}, s \leq t, d X_{s}, s<t: d A_{s}=1\right\}_{t \geq 0}$, and the investment process $K=\left\{d K_{t} \geq 0\right\}_{t \geq 0}$ and the monetary compensation process $C=$ $\left\{d C_{t} \geq 0\right\}_{t \geq 0}$ are measurable with respect to $\left\{d \hat{X}_{s}, s \leq t, d X_{s}, s \leq t: d A_{s}=1\right\}_{t \geq 0}$. Given mechanism $\Gamma$ and reporting strategy $\hat{X}$, the expected discounted utilities of the division manager and the headquarters are

$$
\begin{gathered}
\mathbb{E}^{\hat{X}}\left[\int_{0}^{\infty} e^{-\rho t}\left(\gamma d K_{t}+d C_{t}\right)\right] \\
\mathbb{E}^{\hat{X}}\left[\int_{0}^{\infty} e^{-r t}\left(V\left(d K_{t}, d X_{t}\right) d N_{t}-d K_{t}-d C_{t}-c d A_{t}\right)\right] .
\end{gathered}
$$

The reporting strategy $\hat{X}$ of the division manager is incentive compatible if and only if it maximizes her expected discounted utility (4) given mechanism $\Gamma$. A direct mechanism $\Gamma$ is truth-telling if the truth-telling reporting strategy $\hat{X}=X$ is incentive compatible. The goal is to find a truth-telling direct mechanism $\Gamma=(A, K, C)$ that maximizes the expected discounted utility of the headquarters (5) subject to delivering the division manager the initial expected discounted utility of at least $R$.

\section{Derivation of an Optimal Mechanism}

In this section, I solve for the optimal truth-telling direct mechanism using martingale techniques similar to those in DeMarzo and Sannikov (2006). The idea is to summarize all relevant prior history at time $t$ using a single state variable and show that its evolution represents the division-manager's incentives. 


\subsection{Incentive Compatibility}

Using the standard argument (e.g., Townsend (1979)), it is easy to show that it is optimal to punish the division manager as much as possible if the audit reveals that her report is not truthful. Maximum punishment implies that $d K_{t}=0$ and $d C_{t}=0$ for any $t$ following a nontruthful report exposed by the audit. Intuitively, because lying never occurs in equilibrium, there is no cost of imposing the maximum punishment for lying. ${ }^{21}$ Given this result, in what follows I focus only on histories in which audit decisions always confirm reports of the division manager. Thus, the past history can be summarized using only the report process $\left(d \hat{X}_{t}\right)_{t \geq 0}$. When deciding what report $d \hat{X}_{t}$ to send to the headquarters, the division manager evaluates how the report will affect her expected utility. Let $W_{t}(\hat{X})$ be defined as the expected future utility of the division manager at time $t$ after a history of reports $\left\{d \hat{X}_{s}, s \leq t\right\}$, conditional on reporting truthfully in the future:

$$
W_{t}(\hat{X})=\mathbb{E}_{t}\left[\int_{t}^{\infty} e^{-\rho(s-t)}\left(\gamma d K_{s}+d C_{s}\right)\right]
$$

In other words, $W_{t}(\hat{X})$ is the expected future utility that the mechanism "promises" to the division manager at time $t$ following history $\hat{X}$. Thus, I will equivalently refer to $W_{t}(\hat{X})$ as the promised utility of the division manager. It is convenient to denote the left-hand limit of (6) at time $t$ by $W_{t-}: W_{t-} \equiv \lim _{s \uparrow t} W_{s}$. The following lemma uses the martingale representation theorem to represent the evolution of $\left(W_{t}\right)_{t \geq 0}$ :

Lemma 1. At any moment of time $t \geq 0$, the evolution of the division manager's promised utility $W_{t}$ following her report $d \hat{X}_{t}$ is

$$
d W_{t}=\rho W_{t-} d t-\gamma d K_{t}-d C_{t}+H_{t}\left(d \hat{X}_{t}\right)-\left(\lambda \int_{\underline{\theta}}^{\bar{\theta}} H_{t}(\theta) f(\theta) d \theta\right) d t
$$

where $H_{t}\left(d \hat{X}_{t}\right)$ is the sensitivity of the division manager's utility to her report satisfying: (i) $H_{t}(0)=0$; and (ii) for any fixed $\theta \in\{0\} \cup \Theta, H_{t}(\theta)$ is $\mathcal{F}$-predictable.

\footnotetext{
${ }^{21}$ The model can be easily extended to settings in which maximum punishment is not possible. In particular, in an extension of the model in Section 6.4, maximum punishment is not possible because of the ability of the parties to renegotiate the mechanism. In general, limited punishment lowers efficiency of audit but has no effect on optimality of a budgeting mechanism with threshold division of authority.
} 
Equation (7) reflects the martingale property of the total expected utility of the division manager discounted to the initial date. In $(7), \gamma d K_{t}$ is the utility that the division manager obtains from investment at time $t, d C_{t}$ is the utility that the division manager obtains from monetary compensation at time $t$, and $d W_{t}$ is the change in the expected future utility. The martingale condition states that the sum of these three terms less the discounting adjustment $\left(\rho W_{t-} d t\right)$ is zero on average. Function $H_{t}\left(d \hat{X}_{t}\right)$ represents the sensitivity of the division manager's utility to her particular report. Condition $H_{t}(0)=0$ states that if the division manager reports the absence of an investment project, which happens with probability one over any infinitely short time interval, then the evolution of the division manager's lifetime expected utility does not experience a jump. In contrast, if the division manager reports the availability of an investment project, then her lifetime expected utility changes by $H_{t}\left(d \hat{X}_{t}\right)$, where $d \hat{X}_{t}$ is the reported quality of the project. Notice that, as mentioned above, equation (7) describes the evolution of $W_{t}$ only along histories, in which audits, if they occur, always confirm reports of the manager. If the audit decision at time $t$ reveals that the division manager's report is not truthful, then her expected future utility $W_{t}$ goes down to zero, because maximum punishment is optimal.

In the optimal mechanism, the division manager must always find it optimal to send a truthful report: $d \hat{X}_{t}=d X_{t}$. In deciding what report to send, the division manager evaluates how it will affect her lifetime expected utility. Depending on report $d \hat{X}_{t}$, the headquarters may audit or not audit it. Let $D_{t}^{A}=\left\{d \hat{X}_{t} \mid d A_{t}=1\right\}$ and $D_{t}^{D}=\left\{d \hat{X}_{t} \mid d A_{t}=0\right\}$ be the "audit" and "do not audit" regions of reports at time $t$, respectively. Because of positive costs of audit, it is never optimal to audit if the division manager reports that there is no project. Therefore, $\{0\} \in D_{t}^{D}$. First, consider any other realization of $d X_{t}$ that belongs to the "do not audit" region $D_{t}^{D}$. To have incentives to reveal $d X_{t}$ truthfully, the division manager must find it suboptimal to report any $d \hat{X}_{t} \neq d X_{t}$. Clearly, the division manager never finds it optimal to send a report from the "audit" region, since she will be audited and punished for lying. To have incentives not to send a non-truthful report from the "do not audit" region, any report from this region must have the same effect on the division manager's utility. Indeed, if this were not the case, the division manager would find it optimal to report $d \hat{X}_{t}$ that has the highest effect, whenever any $d X_{t}$ from the "do not region" is realized. Because the division manager is never audited when she reports that the investment project is not available and $H_{t}(0)=0$, it must be the case that $H_{t}\left(d \hat{X}_{t}\right)=0$ for any report from the "do not audit" region $D_{t}^{D}$. Second, consider any realization of $d X_{t}$ that belongs to the "audit" region $D_{t}^{A}$. 
Again, the division manager never finds it optimal to send a non-truthful report from the "audit" region, since she will be audited and punished for lying. To have incentives not to send a report from the "do not audit" region, the effect of reporting $d X_{t}$ must be at least the same as the effect of sending a report from the "do not audit" region. Therefore, truth-

telling implies $H_{t}\left(d \hat{X}_{t}\right) \geq 0$ for any report from the "audit" region $D_{t}^{A}$. These conclusions are summarized in the following lemma:

Lemma 2. For any time $t \geq 0$, truth-telling is incentive compatible if and only if:

(a) $\forall d \hat{X}_{t} \in D_{t}^{D}: H_{t}\left(d \hat{X}_{t}\right)=0$

(b) $\forall d \hat{X}_{t} \in D_{t}^{A}: H_{t}\left(d \hat{X}_{t}\right) \geq 0$.

\subsection{Solution of the Optimization Problem}

Having derived the incentive compatibility conditions, I can use the dynamic programming approach to determine optimal investment, monetary compensation, and audit strategies subject to delivering the agent any expected utility $W$ and ensuring that truth-telling is optimal. The problem is solved in two steps. On the first step, I solve for optimal investment and monetary transfers taking the audit region as given. On the second step, I optimize over the audit strategies. I present a heuristic argument here and verify it in the proof of Proposition 1 in the appendix. Let $P(W)$ denote the value function of the headquarters, i.e., the highest value to the headquarters that can be obtained from a mechanism that provides expected discounted utility of $W$ to the division manager. In what follows I assume that the value function $P(W)$ is concave. Concavity is a natural property, which intuitively means that the lower the manager's share of the total payoff $P(W)+W$, the higher the agency costs of the relationships. As a consequence, the benefit to the headquarters' value function from lowering the manager's promised utility decreases as $W$ falls. Concavity holds in all numerical examples I have considered and can be generally ensured by letting the mechanism specify a random promised utility to the division manager. ${ }^{22}$

Let $W^{c}$ be the lowest $W$ at which $P^{\prime}(W)=-1 .{ }^{23}$ Because the headquarters can provide the agent with utility by compensating the division manager with immediate monetary

\footnotetext{
${ }^{22}$ See DeMarzo and Fishman (2007a) for a detailed description of how the value function can be "concavified" by allowing for random promised payoffs to the agent. For simplicity, I assume that the value function is concave even without randomization.

${ }^{23} W^{c}=\infty$ if $P^{\prime}(W)>-1$ for all $W$.
} 
transfers, it must be the case that $P^{\prime}(W) \geq-1$. By concavity of the value function, it is optimal to make compensation transfers if and only if $W>W^{c}$ :

Property 1. The headquarters makes payments to the division manager if and only if her promised utility is at least $W^{c}$, which satisfies $P^{\prime}\left(W^{c}\right)=-1$. The optimal payments are given by

$$
d C_{t}=\max \left\{W_{t}-W^{c}, 0\right\}
$$

Property 1 is a standard property of many dynamic principal-agent models with riskneutral agents. ${ }^{24}$ Intuitively, it states that it is cheaper to compensate the division manager with promises when her promised utility is low, and it is cheaper to make direct payments in cash if the promised utility is high. In particular, (8) implies that on any sample path $W_{t}$ never exceeds $W^{c}$, except for the starting point if $W_{0}>W^{c}$.

Consider region $W<W^{c}$. Because the discount rate of the headquarters is $r$, the expected instantaneous change in the headquarters' value function is equal to

$$
r P\left(W_{t-}\right) d t
$$

This expression must be equal to the sum of the expected flow of value over the next instant and the expected change in $P(W)$ due to the evolution of $W$. Clearly, any positive investment is not optimal if the division manager reports that no project arrives. Thus, the expected flow of value over the next instant is equal to

$$
\lambda d t \int_{\underline{\theta}}^{\bar{\theta}}\left(V\left(d K_{t}, \theta\right)-d K_{t}-c d A_{t}\right) f(\theta) d \theta
$$

To evaluate the expected instantaneous change in $P(W)$, I can use Itô's lemma and the

\footnotetext{
${ }^{24}$ E.g., the same property is shared by optimal contracts in Clementi and Hopenhayn (2006), DeMarzo and Sannikov (2006), Tchistyi (2006), DeMarzo and Fishman (2007a, 2007b), Piskorski and Westerfield (2010), Piskorski and Tchistyi (2010), and Biais et al. (2010).
} 
evolution of $W$ described by (7). Applying Itô's lemma (see, e.g., Shreve (2004)) yields

$$
\begin{aligned}
\mathbb{E}\left[d P\left(W_{t}\right)\right]= & {\left[\rho W_{t-} d t-\left(\lambda \int_{\underline{\theta}}^{\bar{\theta}} H_{t}(\theta) f(\theta) d \theta\right) d t\right] P^{\prime}\left(W_{t-}\right) } \\
& +\lambda d t \int_{\underline{\theta}}^{\bar{\theta}}\left[P\left(W_{t-}+H_{t}(\theta)-\gamma d K_{t}\right)-P\left(W_{t-}\right)\right] f(\theta) d \theta .
\end{aligned}
$$

The first term in (11) corresponds to the drift of $W$ and the second term corresponds to the jump due to a potential arrival of an investment project. Combining (11) with (10) and equating their sum to (9) leads to the following Hamilton-Jacobi-Bellman equation on the headquarters' value function $P(W)$ :

$$
\begin{aligned}
r P(W)= & \max _{\left\{k_{\theta}, a_{\theta}, h_{\theta}\right\}_{\theta \in \Theta}}\left\{\lambda \int_{\underline{\theta}}^{\bar{\theta}}\left(V\left(k_{\theta}, \theta\right)-k_{\theta}-c a_{\theta}\right) f(\theta) d \theta\right. \\
& +\left[\rho W-\left(\lambda \int_{\underline{\theta}}^{\bar{\theta}} h_{\theta} f(\theta) d \theta\right)\right] P^{\prime}(W) \\
& \left.+\lambda \int_{\underline{\theta}}^{\bar{\theta}}\left[P\left(W+h_{\theta}-\gamma k_{\theta}\right)-P(W)\right] f(\theta) d \theta\right\},
\end{aligned}
$$

where the maximization is subject to the constraints $k_{\theta} \geq 0, a_{\theta} \in\{0,1\}$, and the incentive compatibility constraints

$$
\begin{aligned}
& h_{\theta} \geq 0, \text { if } a_{\theta}=1, \\
& h_{\theta}=0, \text { if } a_{\theta}=0 .
\end{aligned}
$$

From (12) it is easy to see that the optimal investment and audit strategies depend on two parameters: quality $\theta$ of the investment project reported by the division manager and the division manager's pre-report promised utility $W$. Let $k^{*}(\theta, W)$ and $a^{*}(\theta, W)$ denote the optimal investment and audit strategies, respectively.

Given (12), I can derive the properties of investment, audit, and the evolution of $W$ under the optimal mechanism. Consider the "audit" region of reports. The first derivative of (12) with respect to $h_{\theta}$ is proportional to

$$
-P^{\prime}(W)+P^{\prime}\left(W+h_{\theta}-\gamma k_{\theta}\right) .
$$


The first term in (15) is the effect of a marginally higher $h_{\theta}$ on the headquarters' value function due to a change in the drift of $W$. Intuitively, if the headquarters promises a higher payoff following a report that is audited, then it must promise a lower payoff following reports that are not audited. The second term in (15) refers to the effect of a marginally higher $h_{\theta}$ on the headquarters' value function due to a change in $W$ upon the arrival of the project. From (15) it follows that (12) is optimized by $h_{\theta}=\gamma k_{\theta}$, whenever $a_{\theta}=1$. Intuitively, if the project is audited, then the incentive compatibility condition is lax because the information of the division manager is verified by the headquarters. As a result, the only role of a positive $h_{\theta}$ is redistribution of the division manager's utility among states. However, these distortions are harmful to the headquarters. As a consequence, for a report that gets audited it is optimal to keep the division manager's expected future utility unaffected. These dynamics contrast with the dynamics of the division manager's expected future utility after reporting a project that does not get audited. In this region, the incentive compatibility condition is binding because the headquarters must rely on the division manager's reports. Indeed, if the project does not get audited, punishing the division manager in the future is the only way to provide incentives not to overstate the prospects of an investment opportunity. As a consequence, to ensure incentive compatibility in the "do not audit" region, the headquarters must reduce the division manager's expected future utility by the amount $\gamma k_{\theta}$ of private benefits acquired from the current project. Combining these two cases and noting that maximum punishment is optimal following the audit of a non-truthful report proves the following property:

Property 2. Under the optimal mechanism, the evolution of the division manager's promised utility following a report of project $\theta$ is as follows:

(a) if the report is not audited, then the division manager's promised utility is reduced by the amount $\gamma k_{\theta}$ of private benefits from the project;

(b) if the report is audited and confirmed to be truthful, then the division manager's promised utility is unaffected;

(c) if the report is audited and turns out to be non-truthful, then the division manager's promised utility is reduced to zero.

Using this result, it is possible to derive the optimal investment as a function of the quality of the investment project $\theta$ and the division manager's promised utility $W$ in the "audit" and 
"do not audit" regions. Taking the first derivative of (12) with respect to $k_{\theta}$ yields

$$
\begin{aligned}
\frac{\partial V\left(k_{\theta}, \theta\right)}{\partial k}-1-\gamma P^{\prime}\left(W-\gamma k_{\theta}\right) & =0, \text { if } a_{\theta}=0, \\
\frac{\partial V\left(k_{\theta}, \theta\right)}{\partial k}-1-\gamma P^{\prime}(W) & =0, \text { if } a_{\theta}=1 .
\end{aligned}
$$

Concavity of $V(k, \theta)$ and $P(W)$ ensures that each equation has a unique solution. According to (16) - (17), the optimal investment policy maximizes firm value subject to the financing constraint implied by the agency problem. The first two terms in (16) - (17) correspond to the net present value of a marginal dollar invested in the project. The third term in (16) (17) corresponds to the additional effect due to financing constraints implied by the agency problem. Thus, the optimal investment policy satisfies the following property:

Property 3. Let $k^{d}(\theta, W)$ and $k^{a}(\theta, W)$ denote the solutions of (16) and (17), respectively. Then, the optimal investment policy is

$$
k^{*}(\theta, W)= \begin{cases}k^{d}(\theta, W), & \text { if } a^{*}(\theta, W)=0 \\ k^{a}(\theta, W), & \text { if } a^{*}(\theta, W)=1\end{cases}
$$

The optimal investment policy satisfies three natural properties. First, both $k^{d}(\theta, W)$ and $k^{a}(\theta, W)$ are increasing functions of $\theta$, implying that, other things equal, investment is higher if the quality of the project is higher. Second, both $k^{d}(\theta, W)$ and $k^{a}(\theta, W)$ are increasing functions of $W$, implying that, other things equal, more capital is invested if the promised utility of the division manager is higher. This property is intuitive: a higher promised utility of the division manager implies higher expected empire-building private benefits, which translate into higher investment in a given project. The effect of $W$ on optimal investment is uniquely determined by the slope of the value function at the post-investment promised utility of the division manager. When the post-investment promised utility of the division manager is low, this slope is positive, so optimal investment is below the NPV-maximizing level of investment $k^{0}(\theta)$. The opposite is true when the post-investment promised utility of the division manager is high. Finally, $k^{a}(\theta, W)>k^{d}(\theta, W)$, meaning that, other things equal, investment is higher if the investment project is audited. This property follows from the result that investment lowers the promised utility of the division manager only if the project is not audited.

Finally, it remains to solve for the optimal audit policy. Optimizing (12) with respect to 
$a_{\theta} \in\{0,1\}$ leads to $a^{*}(\theta, W)=1$ if and only if

$$
\begin{aligned}
& V\left(k^{a}(\theta, W), \theta\right)-k^{a}(\theta, W)-\gamma k^{a}(\theta, W) P^{\prime}(W) \\
& -\left[V\left(k^{d}(\theta, W), \theta\right)-k^{d}(\theta, W)+P\left(W-\gamma k^{d}(\theta, W)\right)-P(W)\right] \geq c .
\end{aligned}
$$

The intuition behind (19) is simple. The left-hand side of (19) is the marginal benefit of the audit in that the firm's agency constraints are reduced. The right-hand side of (19) is the cost of audit. Audit is optimal when the former exceeds the latter. In the appendix, I show that the left-hand side of (19) is a strictly increasing function of $\theta \in \Theta$. Intuitively, if the quality of the project is higher, the amount of optimal investment in it is higher. However, higher investment implies a higher increase in financing constraints if the project is not audited. At some point $\theta^{*}(W)$, this increase becomes sufficiently high so that audit is optimal if and only if the reported quality of the project is above this point. This result is summarized in the following property:

Property 4. There exists at most one point $\theta^{*}(W) \in \Theta$ at which (19) holds as equality. If the left-hand side of (19) exceeds c for all $\theta \in \Theta$, let $\theta^{*}(W)=\underline{\theta}$. If the left-hand side of (19) is below $c$ for all $\theta$, let $\theta^{*}(W)$ be any point above $\bar{\theta}$. Then, the optimal audit strategy is

$$
a^{*}(\theta, W)= \begin{cases}0, & \text { if } \theta<\theta^{*}(W), \\ 1, & \text { if } \theta \geq \theta^{*}(W)\end{cases}
$$

Combining Property 4 with Properties 1-3 leads to the following evolution of investment, audit, and the division manager's promised utility under the optimal direct mechanism. If the division manager reports that no investment project arrives, then her promised future utility accumulates at a certain rate such that the lifetime expected utility of the division manager is a martingale. Once her promised utility reaches threshold $W^{c}$, it does not grow anymore and the division manager gets paid a flow of constant bonus payment such that her promised utility is reflected at $W^{c}$. If the division manager reports an investment project whose quality $\theta$ is sufficiently low, then the headquarters does not audit the report, the firm invests $k^{d}(\theta, W)$, and the expected future utility of the division manager falls by the amount of empire-building private benefits consumed from the investment. Finally, if the division manager reports arrival of an investment project whose quality $\theta$ is sufficiently high, then the headquarters audits the report and, provided that the report is revealed to be truthful, 
the firm invests $k^{a}(\theta, W)$, and does not change the expected future utility of the division manager. The following proposition summarizes these findings:

Proposition 1. The optimal direct mechanism takes the following form. If $R \leq W^{c}$, then the initial value $W_{0}$ is given by $\max \left\{R, W^{*}\right\}$, where $W^{*}$ is the point at which $P(W)$ is maximized. If $R>W^{c}$, then an immediate payment of $R-W^{c}$ is made to the manager, so that the starting point is $W_{0}=W^{c}$. At any $t$, the division manager sends a report $d \hat{X}_{t} \in\{0\} \cup \Theta$. For any $t:$

1. If $d \hat{X}_{t}=0$ (i.e., the manager reports that no project arrives), then $d K_{t}=0$ and $d A_{t}=0$. When $W_{t-}<W^{c}, W_{t}$ evolves according to

$$
d W_{t}=g\left(W_{t-}\right) W_{t-} d t
$$

where

$$
g(W)=\rho-\lambda \int_{\theta^{*}(W)}^{\bar{\theta}} \frac{\gamma k^{a}(\theta, W)}{W} f(\theta) d \theta,
$$

and $d C_{t}=0$. When $W_{t-}=W^{c}$, the transfer $d C_{t}$ causes $W_{t}$ to reflect at $W^{c}: d C_{t}=$ $g\left(W^{c}\right) W^{c} d t$

2. If $d \hat{X}_{t} \in\left[\underline{\theta}, \theta^{*}\left(W_{t-}\right)\right)$, then $d K_{t}=k^{d}\left(d \hat{X}_{t}, W_{t-}\right), d A_{t}=0$, and $d W_{t}=-\gamma d K_{t}$.

3. If $d \hat{X}_{t} \in\left[\theta^{*}\left(W_{t-}\right), \bar{\theta}\right]$, then $d A_{t}=1$. If the audit reveals that the report is truthful, then $d K_{t}=k^{a}\left(d \hat{X}_{t}, W_{t-}\right)$ and $d W_{t}=0$. If the audit reveals that the report is not truthful, then $d K_{t}=0$ and $d W_{t}=-W_{t-}$.

An example of the headquarters' value function $P(W)$ is shown on Figure 2. It has an inverted U-shaped form. When the division manager's promised utility $W$ is low, little investment occurs to keep the expected private benefits of the manager low. In the extreme case of $W=0$, the headquarters' value function is equal to zero, because $W=0$ requires no investment. As a consequence, when the division manager's promised utility is low enough, a marginal increase in it increases the headquarters' value. When the division manager's promised utility is high enough, a marginal increase in it decreases the headquarters' value. Point $W^{*}$ denotes the promised utility of the division manager at which the headquarters' value is maximized. When the division manager's promised utility is very high so that $W>$ 
$W^{c}$, it is optimal to compensate the manager with monetary transfers. Hence, the slope of the headquarters' value function at these points is equal to -1 . The top panel of Figure 3 plots the optimal investment strategy for a project with quality $\theta=0.5$ as a function of $W$, conditional on the project being audited or not being audited. This figure illustrates the properties of optimal investment described above. The bottom panel of Figure 3 plots the audit strategy under the optimal mechanism. I find numerically that the optimal audit threshold $\theta^{*}(W)$ is typically a decreasing function of $W$. Intuitively, if $W$ is lower, then levels of investment under both "audit" and "do not audit" regimes are lower, which typically translate into a lower benefit from audit. The optimal growth rate of the division manager's promised utility, $g(W)$, is such that its total change is equal to the division manager's discount rate $\rho$. Because the optimal audit threshold is typically a decreasing function of $W$, the optimal growth rate of the division manager's promised utility is also typically a decreasing function of $W$ : a higher fraction of projects audited implies a higher expected increase in the division manager's total utility upon project arrival, so the growth rate of the division manager's utility in the absence of project arrival must be lower.

\section{Implementation}

By the revelation principle, the direct mechanism in Proposition 1 is optimal in the class of all possible mechanisms. However, it is very complex. Unsurprisingly, organizations of internal capital markets in the real world have little resemblance to the mechanism in Proposition 1. Fortunately, the optimal mechanism is not unique. In this section, I show that a simple mechanism, called the budgeting mechanism with threshold division of authority, is equivalent to the mechanism in Proposition 1, meaning that it implements the same policies. This result allows me to conclude that the budgeting mechanism with threshold division of authority is optimal.

I begin by defining a simple budgeting mechanism:

Definition 1 (simple budgeting mechanism). The headquarters allocates a spending account $B_{0}$ to the division manager at the initial date. All investment projects are financed out of the allocated account and are at the discretion of the division manager. At any time $t \geq 0$ the spending account is accumulated with the rate $g_{t}: d B_{t}=g_{t} B_{t} d t$. 
The simple budgeting mechanism has two features. The first feature is that all investment decisions are completely delegated: the division manager has full discretion to invest any amount in any investment project provided that she stays within the limit of the spending account. Any investment reduces the account balance by the amount of investment. The second feature is that the size of the spending account is rigid meaning that the division manager cannot get extra financing even if it leads to passing by profitable investment opportunities. The simple budgeting mechanism has two parameters: the initial size of the spending account $B_{0}$ and the accumulation rate $g_{t}$.

The budgeting mechanism with threshold division of authority augments the simple budgeting mechanism with an additional feature. Specifically, it divides the pool of investment projects into small investment projects, handled by the division manager and financed out of the division manager's spending account, and large investment projects, passed to the headquarters and financed out of the headquarters' resources:

Definition 2 (budgeting mechanism with threshold division of authority). The headquarters allocates a spending account $B_{0}$ to the division manager at the initial date and allows to use it at the manager's discretion to finance investment projects. At any time $t \geq 0$ the spending account is accumulated with the rate $g_{t}$. In addition, the headquarters specifies boundary $k_{t}^{*}$ on the size of individual projects such that at any time $t \geq 0$ the division manager has an option to pass the project to the headquarters claiming that it deserves the investment above $k_{t}^{*} \cdot{ }^{25}$ Upon the receipt of the project, it gets audited by the headquarters. If the audit confirms that the project indeed deserves the investment above $k_{t}^{*}$, the project gets financed fully by the headquarters. If the audit does not confirm that the project deserves the investment above $k_{t}^{*}$, the division manager is punished.

This mechanism separates the decision-making and financing authority between the parties using a threshold on the size of individual projects. If the division manager gets a small investment project, she is not allowed to contact the headquarters and has to finance it out of her spending account. By contrast, if the investment project is large, it can be passed to the headquarters and, after verification, financed completely out of the headquarters' resources. The budgeting mechanism with threshold division of authority has three key parameters: the initial size of the spending account $B_{0}$, the accumulation rate $g_{t}$, and the threshold on the

\footnotetext{
${ }^{25}$ The "deserved" amount of investment here stands for the amount of investment that maximizes firm value subject to the post-investment budget constraint of the division manager.
} 
size of individual projects that divides authority between the parties $k_{t}^{*}$.

The following proposition establishes the main result of the paper - optimality of the budgeting mechanism with threshold division of authority:

Proposition 2. Consider a budgeting mechanism with threshold division of authority with the following primitives:

1. the threshold $k_{t}^{*}$ on the size of individual projects is

$$
k_{t}^{*}=k^{a}\left(\theta^{*}\left(\gamma B_{t}\right), \gamma B_{t}\right)
$$

2. the spending account is accumulated at the rate $g_{t}=g\left(\gamma B_{t}\right)$, if $B_{t}<B^{c}$, and is not accumulated, if $B_{t}=B^{c}$;

3. the monetary compensation of the division manager is zero, if $B_{t}<B^{c}$, and consists of a flow of constant payments $d C_{t}=g\left(\gamma B^{c}\right) \gamma B^{c} d t$, if $B_{t}=B^{c}$.

Then, the division manager finds it optimal to (i) allocate the account between current and future investment opportunities in the way that maximizes firm value; (ii) pass a project to the headquarters if and only if its optimal level of investment exceeds $k_{t}^{*}$. If, in addition, the size of the initial spending account is equal to $B_{0}=W_{0} / \gamma$, where the value of $W_{0}$ is given in Proposition 1, then this mechanism is optimal.

The intuition behind Proposition 2 is as follows. To provide incentives to invest in the way that maximizes firm value, the headquarters must either audit the division manager or punish her by reducing her promised utility by the amount of private benefits that the division manager obtains from investment. If the project's quality is low, the latter tool is optimal and can be implemented using a spending account. Because investing from the account reduces its balance by the amount of investment, the spending account punishes the division manager in the future for high investment today. Moreover, because the division manager's private benefits are proportional to the amount of investment, the decrease in the division manager's promised utility is exactly equal to the amount of private benefits consumed from current investment. As a consequence, the division manager is indifferent between all ways of allocating her account between the current and future investment projects. In particular, she has incentives to do what is in the best interests of the firm. 
This role of a spending account is similar to that of a credit line and cash reserves in prior literature that studies models of cash flow diversion (DeMarzo and Sannikov (2006), DeMarzo and Fishman (2007), Biais et al. (2007)). The current balance of the spending account acts as a "memory device," keeping track of all payoff-relevant information in the prior history. As shown in Section 3, all relevant prior history can be summarized using a single state variable - the promised utility of the division manager. The fundamental idea behind the implementation in Proposition 2 is that there is a one-to-one correspondence between the amount remaining on the division's spending account and the promised utility of the division manager. A gradual accumulation of the spending account in the absence of investment corresponds to an increase in the division manager's promised utility. When the division manager draws on her spending account to finance investment activity, her expected utility from future investment activity goes down. Credit line works in a similar vein in the principal-agent models of DeMarzo and Sannikov (2006) and DeMarzo and Fishman (2007): using the credit line to cover losses corresponds to decreases in the agent's promised utility, while paying the credit line in times of profits corresponds to increases in the agent's promised utility. In Biais et al. (2007), this role is played by cash reserves: an increase (decrease) in the cash balance corresponds to an increase (decrease) in the agent's expected utility.

However, the incentive role of a spending account comes at a cost. Specifically, higher current investment decreases the remaining allocation for future investment, and thus constrains future investment activity. If the amount of investment in the current project is high enough, the headquarters finds it optimal to audit the division manager instead and finance the project without the use of the division manager's resources. This outcome is implemented through giving the division manager an option to pass the project to the headquarters claiming that the optimal investment exceeds the threshold. Because the division manager gets financing "for free," she finds it optimal to pass the project to the headquarters if the optimal investment is indeed above the threshold. However, because all projects passed to the headquarters are audited, the division manager has no incentives to pass the project to the headquarters if the optimal investment is below the threshold. The optimal threshold (23) is such the audit policy implied by this mechanism coincides with the audit policy in Proposition 2.

While under the optimal mechanism financing authority is separated by a threshold on the size of individual projects, optimality does not make unique implications about which party decides on the level of investment after the project is audited. Under the implementation described above, the headquarters audits the project and makes the decision regarding the amount of investment on its own. In this case, communication between the division manager 
and the headquarters is limited to passing the projects from one party to the other. An equivalent implementation is that the division manager files a capital request for a certain amount of capital, the headquarters audits the capital request, allocates the capital if the audit confirms the capital request, and the division manager makes the investment decision on her own. In the model, both implementations lead to the same investment policies. ${ }^{26}$ In practice, however, each implementation has its own advantages and disadvantages. The former implementation involves less communication but requires the ability of the headquarters to commit to the level of investment that maximizes firm value ex ante. The latter implementation does not require this ability but involves more communication between the parties: the division manager not only passes the project to the headquarters but also specifies the exact amount of investment in it.

An example of the headquarters value function as a function of the division's current spending account is shown on Figure 4. From the comparison of Figures 2 and 4, one can easily see the one-to-one correspondence between the division manager's spending account balance $B$ and her expected future utility $W$. In the optimal mechanism, the headquarters gives the initial spending account to the division manager. If the division manager's initial required payoff $R$ is below $W^{*}$, the size of the initial spending account is equal to $B^{*}=W^{*} / \gamma$ - the level at which the headquarters' value is maximized. If the division manager's initial required payoff $R$ is above $W^{*}$ but below $W^{c}$, the size of the initial spending account is equal to $R$. As time goes by, the spending account accumulates at the rate of $g\left(\gamma B_{t}\right)$. If the division manager receives a small investment project, she finances it out of her own spending account. In this case, the size of the remaining spending account balance decreases by the amount of investment. If the division manager receives a large investment project, she passes it to the headquarters. In this case, the headquarters evaluates the project and finances it out of the headquarters' own resources.

\footnotetext{
${ }^{26}$ To see that the second implementation implies the same investment policy, suppose that the headquarters approves capital request for $\Delta$ and allocates it to the division manager. Because the division manager allocates her spending account between the current and future investment projects in the way that maximizes firm value, the size of investment will be the one that maximizes $V(\theta, k)-k+P(\gamma(B+\Delta-k))$, where $B$ is the spending account balance prior to filing the capital request. Knowing this, the headquarters approves the capital request if and only if the requested amount $\Delta$ is exactly equal to the size of investment $k$. The resulting level of investment is equal to $k^{a}(\theta, \gamma B)$.
} 


\section{Discussion}

\subsection{Relation to Observed Organizations of Investment Activity}

The implementation in Proposition 2 captures two features of organization of investment activity in real-world corporations. The first feature is budgeting, i.e., an arrangement in which the upper management allocates a spending account to a lower-level manager and allows the division manager to use it to finance investment projects. In the model, assigning a spending account to the division manager is a tool that punishes the division manager in the future for high current investment: higher investment out of the spending account decreases the remaining allocation, and as a result, reduces expected private benefits of the division manager from future investment. As a consequence, a spending account aligns incentives of the division manager and the headquarters.

The second feature is threshold division of authority between the division and the headquarters. This is also a property of internal capital markets in many real-world corporations. Ross (1986) argues that a typical manufacturing firm sets boundaries on the size of investment that specify the level of the corporate hierarchy at which the investment decision is made. In a typical firm in the sample of Ross (1986), a plant manager has authority to make decisions on investment projects whose size is below $\$ 100,000$, but passes larger projects to the upper levels of the organizational hierarchy. Similar evidence is presented in other surveys. ${ }^{27}$ In the model, this feature arises because the incentive role of a spending account comes at a cost of constraining future investment activity. If the amount of investment in the current project is high enough, the headquarters finds it optimal to provide incentives by auditing the division manager. In this case, full financing of the project by the headquarters is optimal, because it minimizes costly distortions in the spending account.

The budgeting mechanism with threshold division of authority is optimal if the threshold on the size of individual projects that separates authority between the parties is set optimally. From (18) one can see that the optimal threshold is typically path-dependent: it depends on the current spending account balance. The optimal threshold for the example on Figures 2 and 4 is shown on the left panel of Figure 5 (in black). In reality, internal capital markets typically specify a threshold that does not depend on how much the division manager has already spent. Even though such mechanism is not optimal, it is possible to think about it as a simple approximation of the optimal mechanism. Indeed, incentive compatibility of investment policy

\footnotetext{
${ }^{27}$ Gitman and Forrester (1977), Slagmulder, Bruggeman, and van Wassenhove (1995), Ryan and Ryan (2002), Akalu (2003).
} 
that maximizes firm value does not depend on the threshold, so a suboptimal threshold has only a limited effect on firm value. It can be the case that real-world corporations sacrifice a little in firm value to have greater simplicity in the form of a uniform threshold. The optimal constant threshold is shown on the left panel of Figure 5 (in blue).

It is worthwhile to consider two special cases of the implementation in Proposition 2. For the first special case, consider the case of infinitely high costs of audit, $c \rightarrow \infty$. In this case, a simple budgeting mechanism is optimal. Intuitively, if the audit is prohibitively costly, then the only way to provide the division manager with incentives not to overinvest is to commit to a fixed expected amount of empire building private benefits. This can be achieved in the form of allocating a rigid spending account. Empirically, capital budgets with complete delegation of investment authority are used by some corporations (e.g., Slagmulder, Bruggeman, and van Wassenhove (1995)). My model suggests that this arrangement is especially likely to be in corporations, in which the upper management is unable to verify the spending needs of lower-level managers at low cost. In particular, this is likely to be the case, when the size of the division is small and when the division manager has a narrow expertise, e.g., a focus on a very specific location or industry.

For the second special case, consider the case on zero costs of audit, $c=0$. In this case, complete centralization in which the headquarters makes decisions on all investment projects is optimal. This form of organization of investment activity is also sometimes observed

(e.g., Slagmulder, Bruggeman, and van Wassenhove (1995)). The model suggests that this arrangement is especially likely to be in corporations, in which the supervisor has low costs of verifying subordinates. This can be because the expertise of the supervisor is very close to that of the subordinate or because the supervisor has an intrinsic preference for making decisions on her own. This prediction seems to be consistent with observations. For example, the sample in Bloom et al. (2010) contains a textile plant in India, in which the plant manager is required to discuss all spending decisions, including very minor ones, with his supervisor, the division manager, who lives in a building next to the plant.

\subsection{Implications for Corporate Investment}

It is worthwhile to compare investment implied by the optimal mechanism to the NPVmaximizing level of investment $k^{0}(\theta)$. One of the key results of my model is that the optimal level of investment is path-dependent. Both overinvestment and underinvestment relative to $k^{0}(\theta)$ can occur, and the specific effect depends on the past history. For example, consider 
a division, whose spending account balance after it invests in a certain project exceeds $B^{*}$. Because in this case firm value is a decreasing function of the division's spending account balance, the marginal effect on firm value of saving an additional dollar is negative. As a consequence, it is optimal to overinvest relative to the NPV-maximizing level of investment. Intuitively, if the division has too much cash, it is optimal to overinvest in an investment project today, because this eliminates an even higher overinvestment in the future. By contrast, consider a division, whose spending account balance is below $B^{*}$. In this case, firm value is an increasing function of the division's spending account balance. Consequently, the marginal value of saving an additional dollar is positive. Thus, it is optimal to underinvest in a project relative to the NPV-maximizing level of investment. Intuitively, if the division has little cash, investing of an additional dollar today increases financing constraints in the future, so underinvestment relative to $k^{0}(\theta)$ is optimal, as it reduces future financing constraints.

This path-dependence has three implications. First, a positive relation between cash balances and investment activity observed empirically is not necessarily a consequence of external financing constraints of the firm. Indeed, the model is based on the assumption that the headquarters has access to unlimited resources at no cost. The positive relation between cash balances and investment arises because of internal financing constraints, which are strategically introduced by the headquarters to alleviate intra-firm agency conflicts. Second, the optimal mechanism implies corporate socialism, which is common in some corporations (e.g., Graham, Harvey, and Puri (2010)). Specifically, consider two divisions that get the same investment project at time $t$. Then, if the first division had fewer projects in the past than the second division, it will invest more. Even though this property is not optimal ex post, it creates incentives to not overstate prospects of investment projects ex ante. Third, because the division manager's spending account balance decreases only if the project is not passed to the headquarters, the optimal mechanism implies that investment by the division is negatively correlated over time, while investment by the headquarters is not correlated over time.

While there can be both overinvestment and underinvestment relative to the level that maximizes NPV, there is underinvestment relative to the size of investment that maximizes the sum of the project NPV and the division manager's empire-building benefits. This result follows from $P^{\prime}(\gamma B)>-1$ for all points along the possible histories except for $B=B^{c}$ at which $P^{\prime}(\gamma B)=-1$. This result is similar to Bernardo, Cai, and Luo (2001) and is different from Harris and Raviv (1996, 1998), where overinvestment occurs for the lowest quality projects and underinvestment occurs for the highest quality project. The reason for this is the ability of the division manager's monetary compensation to respond to her private 
information. If the division manager's monetary compensation can be a function of his private information, investing above the level that maximizes the joint surplus is suboptimal, because in this case it is cheaper to pay the equivalent utility to the agent in the form of monetary compensation. This is the case in the model of Bernardo, Cai, and Luo (2001), in which managers with different investment projects choose different compensation contracts, but not the case in the models of Harris and Raviv $(1996,1998)$, in which monetary compensation of the manager is required to be independent of her report. Even though the setup of my model is more similar to Harris and Raviv $(1996,1998)$ than to Bernardo, Cai, and Luo (2001), I get a different result, which highlights the difference between static and dynamic interactions.

Finally, an interesting property of the optimal organization of investment activity is that investment decisions made on the division level are more financially constrained than investment decisions made on the headquarters level. It is easy to see this from (16) and (17): by the concavity of the value function, $P^{\prime}(\gamma(B-k))$ is always higher than $P^{\prime}(\gamma B)$. Intuitively, unlike investment decisions made at the division level, investment decisions made at the headquarters level are not financed using the division's spending account. As a consequence, while the former decisions increase future financing constraints of the division, the latter decisions do not. Because of this difference, it is optimal to treat projects financed by the division more "harshly" than projects financed by the headquarters. Empirically, this feature is common in corporations. For example, divisions are known to use higher discount rates when making their investment decisions than corporate investment committees (Ross (1986)).

\section{Extensions}

In this section, I consider a number of extensions of the model.

\subsection{Multiple Audit Technologies}

The main model assumes that the headquarters has access to only one audit technology. A more natural assumption, however, is that there exist multiple audit technologies that differ in their costs and efficiency. For example, Ross (1986) provides evidence that some large projects of the division are passed to the corporate investment committee while the others are passed to the CEO. One can think interpret these two options as two audit technologies with audit by the CEO being more expensive (e.g., because the time of the CEO is likely to be more expensive) but also more efficient than audit by the corporate investment committee 
(e.g., because of the CEO's knowledge and experience or a potential agency conflict between the $\mathrm{CEO}$ and the corporate investment committee). This subsection studies how the optimal organization of investment activity in Section 4 changes when the headquarters has access to two audit technologies.

Specifically, suppose that there are two audit technologies. Technology 2 is efficient but expensive: it costs $c_{2}$ and reveals $d X_{t}$ to the headquarters with certainty. By contrast, technology 1 costs $c_{1} \in\left(0, c_{2}\right)$ but is less efficient. Specifically, with probability $p$, the headquarters learns $d X_{t}$ with certainty (i.e., the audit is successful); with probability $1-p$, the headquarters does not learn anything (i.e., the audit is unsuccessful).

In the appendix, I study the model in detail and summarize the findings in Proposition 3 , which establishes optimality of a budgeting mechanism with two thresholds on the size of individual projects. The division of authority is illustrated in Figure 6. If the division manager obtains a small project, the division manager finances the project out of her spending account. If the division manager obtains a large project, so that the optimal investment in it exceeds $k_{t}^{*}$, she passes it to the headquarters. If the optimal investment in the project exceeds $k_{t}^{* *}$, the project is audited using the expensive audit technology. If the optimal investment in the project is above $k_{t}^{*}$ but below $k_{t}^{* *}$, the headquarters audits the project is audited using the cheap audit technology. If the audit is successful, the headquarters verifies the project and finances it fully. Interestingly, the headquarters provides financing for the project even if the audit does not reveal $d X_{t}$ to the headquarters. If the division manager reports that the optimal investment in the project is below $k_{t}^{* * *} \in\left[k_{t}^{*}, k_{t}^{* *}\right]$, then the headquarters fully finances the project even if the audit is unsuccessful. If the division manager reports that the

optimal investment in the project is above $k_{t}^{* * *}$ and the headquarters does not learn any new information from the audit, then the project is co-financed: the headquarters finances $k_{t}^{* * *}$ and the division manager finances the rest out of her spending account. The findings of this extension are consistent with the use of multiple thresholds that separate authority among levels of the organizational hierarchy (e.g., Ross (1986)).

\subsection{Multiple Categories of Projects}

The main model assumes that the amount of private benefits that the division manager gets from investment of $d K_{t}$ is the same for all projects. This assumption is important for incentive compatibility of the budgeting mechanism with threshold division of authority. If the division manager prefers to spend her account on one project over the others, she no 


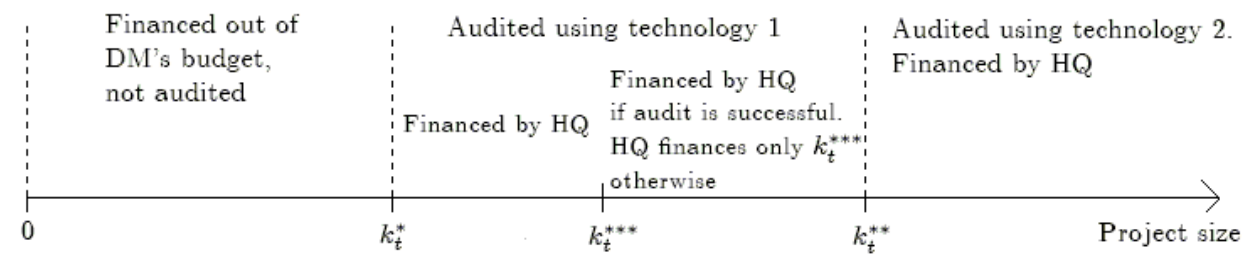

Figure 6. Optimal division of authority in a model with two audit technologies.

longer has incentives to invest in the way that maximizes firm value subject to the budget constraint. This assumption is natural when all investment projects belong to the same category. In practice, however, division managers deal with projects that may be associated with different private benefits. For example, the private benefits are likely to be higher if the division manager spends resources on renovation of her office than on a marketing campaign. In this subsection, I consider an extension of the model that approaches this issue.

Specifically, suppose that there are two categories of projects, a category $L$ with low private benefits $\gamma_{L} \in(0,1)$ and a category $H$ with high private benefits $\gamma_{H} \in\left(\gamma_{L}, 1\right)$. Letting $\left(d K_{L, t}\right)_{t \geq 0}$ and $\left(d K_{H, t}\right)_{t \geq 0}$ denote the streams of investment into categories $L$ and $H$, respectively, the utility of the division manager is equal to

$$
\int_{0}^{\infty} e^{-\rho t}\left(\gamma_{L} d K_{L, t}+\gamma_{H} d K_{H, t}+d C_{t}\right)
$$

Analogously to the main model, assume that an investment opportunity in category $i \in$ $\{L, H\}$ arrives independently with intensity $\lambda_{i}$ and is characterized by quality $\theta$, which is an i.i.d. draw from a distribution with c.d.f. $F_{i}(\theta)$ and p.d.f. $f_{i}(\theta)$ defined over $\Theta=[\underline{\theta}, \bar{\theta}] .{ }^{28}$

The following proposition shows that the optimality of a budgeting mechanism with threshold division of authority, in which there are two spending accounts with each being used to finance projects of a particular category:

Proposition 4. Consider the following mechanism. The headquarters allocates spending accounts $B_{L, 0}$ and $B_{H, 0}$ to the division at the initial date and allows to use them at the manager's discretion to finance projects in categories $L$ and $H$, respectively. Each account is

\footnotetext{
${ }^{28}$ This extension can be generalized to case of different supports of distributions and different value functions of projects in different categories, as well as to any number $N$ of project categories.
} 
accumulated over time with rate $g_{t}$. The division manager is allowed to transfer funds between account $i \in\{L, H\}$ and account $j \neq i$ at the rate $\gamma_{i} / \gamma_{j}$. In addition, the headquarters specifies thresholds on the size of individual projects in category $i \in\{L, H\}$, such that at any time $t \geq 0$ the division manager has an option to pass the project in category $i$ to the headquarters claiming that it deserves the investment above $k_{i, t}^{*}$. Upon the receipt of the project, it gets audited by the headquarters. If the audit confirms that the project indeed deserves the investment above $k_{i, t}^{*}$, the project gets financed fully by the headquarters. If the audit does not confirm that the project deserves the reported amount, the division manager is punished. If the initial spending account allocations, the accumulation rate $g_{t}$, the thresholds $k_{i, t}^{*}$, and the monetary compensation of the division manager $d C_{t}$ are given by ${ }^{29}$

$$
\begin{aligned}
\gamma_{L} B_{L, 0}+\gamma_{H} B_{H, 0} & =W_{0}, \\
g_{t} & =g\left(W_{t}\right), \text { if } W_{t}<W^{c}, \text { and } g_{t}=0, \text { otherwise, } \\
k_{i, t}^{*} & =k^{a}\left(\theta_{i}^{*}\left(W_{t}\right), W_{t}\right), i \in\{L, H\}, \\
d C_{t} & =\max \left\{W_{t}-W^{c}, 0\right\},
\end{aligned}
$$

where $W_{t}=\gamma_{L} B_{L, t}+\gamma_{H} B_{H, t}$, and $g(\cdot)$ and $\theta_{i}^{*}(\cdot)$ are defined in the appendix, then this mechanism is optimal.

Intuitively, the use of a category-specific spending account does not allow the division manager to strategically invest more in projects with higher private benefits. This makes investment policy that maximizes firm value subject to the budget constraint incentive compatible. This intuition may explain why corporations often use separate spending accounts for different kinds of activities: for example, an account for R\&D, an account for capital investment, an account for office renovation, etc. A feature of the optimal mechanism in the model that is not observed in practice is conversion of funds from one account to the other. In the model, conversion reduces financing constraints of the division by adding flexibility to the spending accounts. Because the rate of conversion is equal to the ratio of private benefits of the division manager from the projects in the two categories, the division manager has no incentives to move funds between the accounts other than to maximize firm value. Practical implementation of conversion is, however, limited, because the headquarters is unlikely to know the exact ratio of private benefits of the division manager. This might explain why the

\footnotetext{
${ }^{29}$ In this and other extensions, $W_{0}$ is defined in the same way as in Proposition 2.
} 
use of conversion is limited in practice.

\subsection{Value-Sensitive Utility of the Division Manager}

Another important assumption of the model is that utility of the division manager depends only on investment and monetary transfers from the headquarters. In particular, this specification implies that the division manager is indifferent between investment projects of different qualities as long as the size of investment is the same. Clearly, this specification is unlikely to hold in many settings. For example, if the division manager has a stock ownership in the firm, then she has a preference for investing more in projects of higher quality. In this case, the spending account with threshold division of authority in Proposition 2 is not optimal. Intuitively, if the division manager has a preference to invest in higher-quality projects, then punishing the manager for the full amount of private benefits from investment, $\gamma d K_{t}$, is too expensive for the headquarters: it is enough to decrease the manager's promised utility by less than that. In the context of the spending account implementation, it is possible to interpret the decrease of the division manager's promised utility by less than $\gamma d K_{t}$ as co-financing of the project by the division manager and the headquarters.

While the budgeting mechanism with threshold division of authority is no longer optimal, it is still a natural mechanism. Note that in the base model the division manager has incentives to allocate the spending account between the current and future investment opportunities in the way that maximizes firm value. If, in addition, the division manager cares about firm value, she also has no incentives to mimasnage the spending account. In this sense, incentive compatibility of the budgeting mechanism with threshold division of authority is robust to preferences of the division manager with respect to firm value. While characterization of the optimal mechanism for the case of the division manager caring about firm value is beyond the scope of this paper, it is likely to rely on the details of the manager's preferences. Therefore, the policies implied by the optimal mechanism are unlikely to be robust to misspecifications in the division manager's preference for firm value. This makes a budgeting mechanism with threshold division of authority a natural (though, not optimal) choice even for corporations, in which division managers care about firm value.

\subsection{Renegotiation-Proofness}

The optimal mechanism derived in the main model is not renegotiation-proof. First, because the division manager never lies in equilibrium, audit is never optimal ex post. The assumption 
of commitment to the audit strategy is reasonable in many settings. For example, the firm can specify the project size threshold in the investment manual of the company, and the upper management may find it optimal to stick to the pre-specified procedures because of either reputational concerns or the threat of being punished by an even higher authority, such as the CEO or a large shareholder. Second, when the promised value of the division manager is low enough so that $P^{\prime}(W)>0$, both the division manager and the headquarters have incentives to renegotiate the agreement by increasing the promised utility of the division manager. In the context of the budgeting implementation, renegotiation is achieved by increasing the size of the division manager's spending account when it falls low enough.

In practice, it may be difficult to for the headquarters commit not to allocate funds in the future when positive-NPV projects are passed by. In this subsection, I solve for the optimal mechanism provided that the parties can commit to the audit strategy but cannot commit not to renegotiate over the promised payoff to the division manager (i.e., the size of the spending account in the budgeting implementation).

To be renegotiation-proof, the mechanism must imply the headquarters' value function that does not have positive slope. Thus, possibility of renegotiation places the lower boundary on the division manager's promised payoff to point $W^{*}$ at which $P^{\prime}\left(W^{*}\right)=0$. Thus, the optimal investment as a function of the quality of the investment project $\theta$ and the division manager's promised value $W$ in the "do not audit" region is equal to

$$
\hat{k}^{d}(\theta, W)=\min \left\{k^{d}(\theta, W), \frac{W-W^{*}}{\gamma}\right\}
$$

where $k^{d}(\theta, W)$ is given by (16). As can be seen from (29), possibility of renegotiation restricts the ability to invest in projects without audit when $W$ is sufficiently low. In particular, when $W=W^{*}$, positive investment is possible only if the project is audited. By analogy with Property 4, the optimal audit strategy is to audit the project if and only if the division manager claims that its quality is sufficiently high. The threshold $\theta^{*}(W)$ is determined by (19), where $\hat{k}^{d}(\theta, W)$ is used in place of $k^{d}(\theta, W)$.

The next proposition shows that allocation of the optimal renegotiation-proof mechanism can also be implemented using a budgeting mechanism with threshold division of authority:

Proposition 5. Consider a budgeting mechanism with threshold division of authority with the following primitives. The threshold on the size of individual projects is equal to 
$k_{t}^{*}=k^{a}\left(\theta^{*}(W), W\right)$. The spending account is accumulated at the rate $g_{t}=g^{r}\left(B_{t}\right)$, where

$$
g^{r}(B)=\left(1+\frac{W^{*}}{\gamma B}\right) \rho-\lambda \int_{\theta^{*}\left(W^{*}+\gamma B\right)}^{\bar{\theta}} \frac{k^{a}\left(\theta, W^{*}+\gamma B\right)}{B} f(\theta) d \theta
$$

if $B_{t}<B^{c}=\left(W^{c}-W^{*}\right) / \gamma$, and is not accumulated, otherwise. The monetary compensation of the division manager is zero, if $B_{t}<B^{c}$, and consists of a flow of constant payments $d C_{t}=g^{r}\left(B^{c}\right)\left(W^{*}+\gamma B^{c}\right) d t$, if $B_{t}=B^{c}$. If, in addition, the size of the initial spending account is equal to $B_{0}=\left(W_{0}-W^{*}\right) / \gamma$, where the value of $W_{0}$ is determined as in Proposition 1 , then this mechanism is optimal among all renegotiation-proof mechanisms.

The optimal renegotiation-proof arrangement is different from the optimal arrangement in Proposition 2 in two dimensions. First, for a given payoff of the division manager $W$, the optimal renegotiation-proof arrangement implies a lower spending account balance: $\left(W-W^{*}\right) / \gamma$ instead of $W$. Thus, the model implies that, other things equal, the size of the division manager's account balance increases in the commitment ability of the headquarters. The second difference concerns the optimal audit policy when the size of the division manager's account balance approaches zero. Under the optimal mechanism in the model with commitment, the headquarters does not audit projects of the division manager in this case. By contrast, under the optimal renegotiation-proof mechanism, the headquarters audits all projects with positive investment when her spending account gets very small.

\subsection{Finite-Horizon Mechanisms}

To preserve stationarity, the main model focused on the infinite-horizon setting, in which case the infinite-horizon spending account was optimal. In practice, however, spending accounts are often limited to finite time intervals (e.g., a year) and managers are not allowed to roll over the unused resources to the next period. While the paper does not study when it is optimal for firms to limit the length of the period, this subsection examines how the optimal mechanism looks like when the spending account is limited to a finite period for an exogenous reason.

Specifically, I suppose that $t \in[0, T]$ and focus on the case in which both parties share the same discount rate $r$. Because the discount rate of the division manager is equal to that of the headquarters, it is optimal to postpone monetary compensation until time $T$. Let $P(W, t)$ be the value function of the headquarters, where $W \in \mathbb{R}_{+}$and $t \in[0, T]$. The same argument 
as in Section 3 leads to the following Hamilton-Jacobi-Bellman equation: ${ }^{30}$

$$
\begin{aligned}
r P(W, t)= & \max _{k_{\theta}, h_{\theta}, a_{\theta}}\left\{\lambda \int_{\underline{\theta}}^{\bar{\theta}}\left(V\left(k_{\theta}, \theta\right)-k_{\theta}-c a_{\theta}\right) f(\theta) d \theta\right. \\
& +\left[r W-\left(\lambda \int_{\underline{\theta}}^{\bar{\theta}} h_{\theta} f(\theta) d \theta\right)\right] P_{W}(W, t)-P_{t}(W, t) \\
& \left.+\lambda \int_{\underline{\theta}}^{\bar{\theta}}\left[P\left(W+h_{\theta}-\gamma k_{\theta}, t\right)-P(W, t)\right] f(\theta) d \theta\right\},
\end{aligned}
$$

where the maximization is subject to constraints (13) - (14) and boundary condition

$$
P(W, T)=-W
$$

This boundary condition states that because the game is over at time $T$, the value of the headquarters at the last date is equal to negative of the payment that the headquarters makes to the division manager at time $T$.

From (31) it is easy to see that the only difference between the finite-horizon problem and the infinite-horizon problem is in the additional state variable $t$. This difference is due to the stationarity of the infinite-horizon problem. Unsurprisingly, as the next proposition shows, the budgeting mechanism with threshold division of authority is also optimal in this case:

Proposition 6. Consider a budgeting mechanism with threshold division of authority with the initial spending account of $B_{0}=W_{0} / \gamma$, the threshold on the size of individual projects that can be passed to the headquarters is $k_{t}^{*}=k^{a}\left(\theta^{*}\left(\gamma B_{t}, t\right), \gamma B_{t}, t\right)$, the accumulation rate of the spending account $g_{t}=g\left(\gamma B_{t}, t\right)$, where functions $k^{a}(\cdot), \theta^{*}(\cdot)$, and $g(\cdot)$ are defined in the appendix. Suppose that at time $T$, the remaining balance of the division manager's spending account converts into monetary compensation with multiple $\gamma$. This mechanism is optimal.

Proposition 6 shows that essentially the same mechanism as in Proposition 2 is also optimal in the finite-horizon model. There are two notable differences between them. First, because the optimization problem of the headquarters is no longer stationary, the optimal accumulation rate of the spending account and the optimal project size boundary depend on how much time remains until the final date $T$. Numerically I find that the project size

\footnotetext{
${ }^{30}$ See the appendix for the details.
} 
boundary increases in $t$. In other words, it is optimal for the headquarters to audit less when there is less time remaining until the end of the contracting period $T$. Intuitively, as time goes by, future investment activity becomes less important for the headquarters. This lowers gains from audit. The second difference is in the monetary compensation policy. Because the discount rates are equal, the optimal compensation policy takes a single payment at the final date. To give incentives not to overspend, the monetary transfer must be at least as low as the monetary equivalent of the utility that the division manager can get by spending the remaining spending account at the final date, i.e., $\gamma B_{T}$. Because $\gamma<1$, compensating the agent directly through monetary transfers is cheaper than compensating the agent indirectly through wasteful investment. This suggests that the "use-it-or-lose-it" feature, which is widespread in budgeting mechanisms in practice, is inefficient because it creates incentives to overspend when the budgeting period approaches the end. In practice, however, introducing the "use-it-or-lose-it" feature may be natural if the headquarters does not know the exact value of $\gamma$. Indeed, if the headquarters overestimates $\gamma$ and offers a conversion rate that is too high, the division manager finds it optimal to pass by all investment projects, wait until time $T$, and convert her remaining account balance into the monetary compensation. Adding the "use-it-or-lose-it" feature precludes such manipulations.

\section{Conclusion}

In this paper, I analyze the optimal organization of investment activity in a firm. For this purpose, I consider a continuous-time principal-agent (headquarters - division manager) framework with three key properties. First, the arrival and quality of investment projects are privately observed by the division manager. Second, the division manager obtains an "empirebuilding" private benefit from each dollar invested. Finally, at any time the headquarters can learn the quality of the current investment project of the division manager at a cost. In this setting, I establish optimality of a relatively simple arrangement, called a budgeting mechanism with threshold division of authority. In this arrangement, the headquarters allocates a spending account to the division manager at the initial date and accumulates it over time. The division manager is given authority to spend her account on the investment activity, provided that she does not go over the allocated amount. In addition, the division manager is given an option to pass the project to the headquarters claiming that the optimal investment in it exceeds the threshold. If the division manager passes the project, it gets audited by 
the headquarters and, if the audit confirms that the project requires an investment above the threshold, it gets financed fully by the headquarters. In equilibrium, this arrangement leads to a separation of authority: small projects are approved locally and are financed out of the division manager's spending account; large projects are passed to the headquarters and are financed out of the headquarters' resources. In the extensions, I study when it is optimal to give separate spending accounts for projects of different types (e.g., a separate spending account for capital investment projects and a separate spending account for advertising), when it is optimal to assign several thresholds on the size of individual projects that separate authority among several levels of the organizational hierarchy, whether the use-it-or-lose feature of many real-world spending accounts is optimal, and what happens if the parties can renegotiate over the arrangement.

While my main focus is on corporate investment, the results of the paper can be applicable to any principal-agent setting, in which the agent privately receives various spending needs over time and has incentives to overspend. For example, the model can be applied to study financing of research-related activities in academic institutions and financing of public projects between several levels of the political hierarchy. 


\section{Appendix A: Proofs}

This appendix provides proofs of all lemmas and propositions except for Proposition 3 (i.e., the model with multiple audit technologies), whose proof is provided in Appendix B.

Proof of Lemma 1. Note that $W_{t}(\hat{X})$ is also the division manager's expected future utility if $\left\{d \hat{X}_{s}, 0 \leq s \leq t\right\}$ were the true realizations that the division manager reported truthfully. Hence, without loss of generality, it is sufficient to prove the lemma for the case of truthful reporting by the division manager. Let $U_{t}(X)$ denote the lifetime expected utility of the division manager, evaluated conditionally on information available at time $t$ :

$$
U_{t}(X)=\int_{0}^{t} e^{-\rho s}\left(\gamma d K_{s}+d C_{s}\right)+e^{-\rho t} W_{t}(X) .
$$

By definition, process $U(X)=\left\{U_{t}(X)\right\}_{t \geq 0}$ is a right-continuous $\mathcal{F}$-martingale. By the martingale representation theorem for marked point processes (e.g., see Theorem 1.13 .2 on pages 25 - 26 in Last and Brandt (1995)), for any $t$ there exists a function $h_{t}(\cdot)$, where $h_{t}(\theta)$ is $\mathcal{F}$-predictable for any fixed $\theta \in \Theta$, such that

$$
d U_{t}= \begin{cases}-\left(\lambda \int_{\underline{\theta}}^{\bar{\theta}} h_{t}(\theta) f(\theta) d \theta\right) d t, & \text { if } t \neq T_{n} \text { for any } n \geq 1, \\ h_{t}\left(\theta_{n}\right)-\left(\lambda \int_{\underline{\theta}}^{\bar{\theta}} h_{t}(\theta) f(\theta) d \theta\right) d t, & \text { if } t=T_{n} \text { for some } n \geq 1 .\end{cases}
$$

For convenience, rescale function $h_{t}(\cdot)$ by factor $e^{\rho t}$ and write it with respect to $d X_{t} \in\{0\} \cup \Theta$, defining it to be zero when $d X_{t}=0$ (i.e., no investment project arrives):

$$
H_{t}\left(d X_{t}\right)=\left\{\begin{array}{cl}
0, & \text { if } d X_{t}=0 \\
e^{\rho t} h_{t}\left(d X_{t}\right), & \text { if } d X_{t} \in \Theta
\end{array}\right.
$$

Notice that $H_{t}\left(d X_{t}\right)$ is $\mathcal{F}$-predictable for any fixed $d X_{t} \in\{0\} \cup \Theta$, because $h_{t}(\theta)$ is $\mathcal{F}$-predictable for any fixed $\theta \in \Theta$ and $H_{t}(0)=0$. Then,

$$
d U_{t}=e^{-\rho t}\left(H_{t}\left(d X_{t}\right)-\left(\lambda \int_{\underline{\theta}}^{\bar{\theta}} H_{t}(\theta) f(\theta) d \theta\right) d t\right) .
$$

Differentiating (33) with respect to $t$,

$$
d U_{t}=e^{-\rho t}\left(\gamma d K_{t}+d C_{t}\right)-\rho e^{-\rho t} W_{t-}(X)+e^{-\rho t} d W_{t}(X) .
$$

Equating (37) with (36) and rearranging the terms yields (7).

Proof of Lemma 2. Consider any $d X_{t} \in D_{t}^{D}$. Report $d X_{t}$ dominates any report $d \hat{X}_{t} \in D_{t}^{A}$, because lying will be exposed and the agent's expected future utility will drop to zero. If the division manager reports $d \hat{X}_{t} \in D_{t}^{D}$ instead of $d X_{t}$, she gains $H_{t}\left(d \hat{X}_{t}\right)-H_{t}\left(d X_{t}\right)$. Therefore, the truthful report of any $d X_{t} \in D_{t}^{D}$ is optimal for the division manager if and only if $H_{t}\left(d \hat{X}_{t}\right)-H_{t}\left(d X_{t}\right) \leq 0$ $\forall d X_{t}, d \hat{X}_{t} \in D_{t}^{D}$. Consequently, $H_{t}\left(d X_{t}\right)$ must be constant for all $d X_{t} \in D_{t}^{D}$. Because $\{0\} \in D_{t}^{D}$ and $H_{t}(0)=0$, truth-telling of any $d X_{t} \in D_{t}^{D}$ is incentive compatible if and only if $H_{t}\left(d X_{t}\right)=$ 
$0 \forall d X_{t} \in D_{t}^{D}$

Consider any $d X_{t} \in D_{t}^{A}$. Again, report $d X_{t}$ dominates any report $d \hat{X}_{t} \in D_{t}^{A}, d \hat{X}_{t} \neq d X_{t}$, because lying will be exposed and the agent's expected future utility will drop to zero. If the division manager reports $d \hat{X}_{t} \in D_{t}^{D}$, she gains $H_{t}\left(d \hat{X}_{t}\right)-H\left(d X_{t}\right)$. Therefore, the truthful report of any $d X_{t} \in D_{t}^{A}$ is optimal for the division manager if and only if $H_{t}\left(d \hat{X}_{t}\right)-H\left(d X_{t}\right) \leq 0$ for all $d X_{t} \in D_{t}^{A}$ and $d \hat{X}_{t} \in D_{t}^{D}$. Because $H_{t}\left(d X_{t}\right)=0$ for all $d X_{t} \in D_{t}^{D}$, as shown in the previous paragraph, truth-telling of any $d X_{t} \in D_{t}^{A}$ is incentive compatible if and only if $H_{t}\left(d X_{t}\right) \geq 0$ $\forall d X_{t} \in D_{t}^{A}$.

Proof of Property 4. First, I show that the left-hand side of (19) is a strictly increasing function of $\theta$. Notice that

$$
\begin{aligned}
& k^{a}(\theta, W)=\arg \max _{k \in \mathbb{R}_{+}}\left\{V(k, \theta)-k-\gamma k P^{\prime}(W)\right\}, \\
& k^{d}(\theta, W)=\arg \max _{k \in \mathbb{R}_{+}}\{V(k, \theta)-k+P(W-\gamma k)\} .
\end{aligned}
$$

Therefore, the left-hand side of (19) can be re-written as

$$
F^{a}(\theta, W)-F^{d}(\theta, W),
$$

where $F^{a}(\theta, W)$ and $F^{d}(\theta, W)$ are defined as

$$
\begin{aligned}
& F^{a}(\theta, W) \equiv \max _{k \in \mathbb{R}_{+}}\left\{V(k, \theta)-k+P(W)-\gamma k P^{\prime}(W)\right\}, \\
& F^{d}(\theta, W) \equiv \max _{k \in \mathbb{R}_{+}}\{V(k, \theta)-k+P(W-\gamma k)-P(W)\} .
\end{aligned}
$$

By the envelope theorem,

$$
\begin{aligned}
\frac{d\left[F^{a}(\theta, W)-F^{d}(\theta, W)\right]}{d \theta} & =\frac{\partial V\left(k^{a}(\theta, W), \theta\right)}{\partial \theta}-\frac{\partial V\left(k^{d}(\theta, W), \theta\right)}{\partial \theta} \\
& =\int_{k^{d}(\theta, W)}^{k^{a}(\theta, W)} \frac{\partial^{2} V(k, \theta)}{\partial k \partial \theta} d k>0
\end{aligned}
$$

because $k^{a}(\theta, W)>k^{d}(\theta, W)$, as follows from (16) and (17), and $\partial^{2} V(k, \theta) / \partial k \partial \theta>0$ by Assumption 1. Therefore, the left-hand side of (19) is an increasing function of $\theta$.

Second, I use this result to conclude that Property 4 holds. There are three cases. First, if the left-hand side of (19) is above $c$ for all $\theta \in \Theta$, then it is optimal to audit all investment projects. Hence, $a^{*}(\theta, W)=1$ for any $\theta \geq \underline{\theta}=\theta^{*}(W)$. Second, if the left-hand side of (19) is below $c$ for all $\theta \in \Theta$, then audit is not optimal for any investment project $\theta$. Hence, $a^{*}(\theta, W)=0$ for any $\theta \leq \bar{\theta}<\theta^{*}(W)$. Finally, if the left-hand side of (19) is neither above nor below $c$ for all $\theta \in \Theta$, then the result that the left-hand side of (19) is a strictly increasing function of $\theta$ implies that there is a unique point $\theta^{*}(W) \in \Theta$ at which (19) holds as equality. In this case, the left-hand side of (19) is below $c$ (hence, $a^{*}(\theta, W)=0$ ) for all $\theta<\theta^{*}(W)$ and above $c$ (hence, $a^{*}(\theta, W)=1$ ) for $\theta \geq \theta^{*}(W)$.

Proof of Proposition 1. The goal is to verify that the direct mechanism conjectured in the proposition indeed maximizes the headquarters' value. The proof follows the logic of standard 
problems in optimal control theory. First, I show the headquarters' expected utility from any incentive compatible mechanism that delivers the initial expected value of $W_{0}$ to the manager is at most $P\left(W_{0}\right)$. Second, I argue that the headquarters' expected utility from the mechanism that satisfies the conditions of the proposition and delivers the initial expected value of $W_{0}$ to the division manager is equal to $P\left(W_{0}\right)$.

Let $G_{t}$ be defined as

$$
G_{t} \equiv \int_{0}^{t} e^{-r s}\left(V\left(d K_{s}, d X_{s}\right) d N_{s}-d K_{s}-d C_{s}-c d A_{s}\right)+e^{-r t} P\left(W_{t}\right) .
$$

Consider an arbitrary direct mechanism satisfying incentive compatibility of truth-telling. Because any mechanism that wastes resources when there is no investment opportunity is clearly suboptimal, it is enough to restrict attention to mechanisms with $d K_{t}=0$ when the division manager reports that no project arrives. The evolution of the division manager's expected future utility implied by the mechanism is given by (7). Applying Itô's lemma, multiplying by $e^{r t}$, and rearranging the terms,

$$
\begin{aligned}
e^{r t} d G_{t}= & V\left(d K_{t}, d X_{t}\right) d N_{t}-d K_{t}-c d A_{t} \\
& -\left(\lambda \int_{\underline{\theta}}^{\bar{\theta}}\left(V\left(d K_{t}, \theta\right)-d K_{t}-c d A_{t}\right) f(\theta) d \theta\right) d t \\
& +\left(\lambda \int_{\underline{\theta}}^{\bar{\theta}}\left(V\left(d K_{t}, \theta\right)-d K_{t}-c d A_{t}\right) f(\theta) d \theta\right. \\
& +\left[\rho W_{t-}-\left(\lambda \int_{\underline{\theta}}^{\bar{\theta}} H_{t}(\theta) f(\theta) d \theta\right)\right] P^{\prime}\left(W_{t-}\right) \\
& \left.+\lambda \int_{\underline{\theta}}^{\bar{\theta}}\left[P\left(W_{t-}+H_{t}(\theta)-\gamma d K_{t}\right)-P\left(W_{t-}\right)\right] f(\theta) d \theta-r P\left(W_{t-}\right)\right) d t \\
& +\left(P^{\prime}\left(W_{t-}\right)-1\right) d C_{t} .
\end{aligned}
$$

The expectation of the sum of the terms on the first two lines is zero. From (12), the sum of the terms on lines 3 - 5 is less than or equal to zero. Finally, because $P^{\prime}\left(W_{t-}\right) \geq-1$, the term on line 6 is less than or equal to zero. Therefore, $\left(d G_{t}\right)_{t \geq 0}$ is a supermartingale. Consider the headquarters' value at time 0 . For any $t<\infty$,

$$
\begin{aligned}
& \mathbb{E}\left[\int_{0}^{\infty} e^{-r s}\left(V\left(d K_{s}, d X_{s}\right) d N_{s}-d K_{s}-d C_{s}-c d A_{s}\right)\right] \\
= & \mathbb{E}\left[G_{t}\right]+e^{-r t} \mathbb{E}\left[\mathbb{E}_{t}\left[\int_{t}^{\infty} e^{-r(s-t)}\left(V\left(d K_{s}, d X_{s}\right) d N_{s}-d K_{s}-d C_{s}-c d A_{s}\right)\right]-P\left(W_{t}\right)\right] \\
\leq & P\left(W_{0}\right)+e^{-r t} \mathbb{E}\left[P^{0}-W_{t}-P\left(W_{t}\right)\right],
\end{aligned}
$$

where $P^{0}$ is the "first-best" value of operations such that the headquarters captures value $V(k, \theta)-$ $(1-\gamma) k$ from each investment, does not audit, and makes a single transfer of $W_{t}$ to the division manager. Therefore, letting $t \rightarrow \infty$,

$$
\mathbb{E}\left[\int_{0}^{\infty} e^{-r s}\left(V\left(d K_{s}, d X_{s}\right)-d K_{s}-d C_{s}-c d A_{s}\right)\right] \leq P\left(W_{0}\right)
$$


Therefore, the headquarters' expected utility from any incentive compatible mechanism that delivers the initial expected value of $W_{0}$ to the manager is at most $P\left(W_{0}\right)$.

Suppose that the mechanism satisfies the conditions of the proposition. Then, (45) implies that $G_{t}$ is a martingale. Therefore, the headquarters' initial expected payoff from the mechanism is $G_{0}=P\left(W_{0}\right)$. Consequently, this mechanism is optimal, since no other direct incentive compatible mechanism can achieve the initial expected payoff above $P\left(W_{0}\right)$.

Proof of Proposition 2. The mechanism is optimal if and only if at any time $t$ it leads to the same investment, audit, monetary compensation policies, and evolution of the division manager's expected future utility as the mechanism in Proposition 1.

First, I show that the evolution of $\gamma B_{t}$ is the same as the evolution of $W_{t}$ in Proposition 1. The starting point is equal to $\gamma B_{0}=W_{0}$ and the evolution of $\gamma B_{t}$ if $B_{t}<B^{c}$ and the division manager does not pass the project to the headquarters is

$$
d\left(\gamma B_{t}\right)=\left(g\left(\gamma B_{t}\right) B_{t} d t-d K_{t}\right) \gamma
$$

Hence, the evolutions of $\gamma B_{t}$ and $W_{t}$ are the same if the investment policies are the same. Because the change in the division manager's utility, $d W_{t}+\gamma d K_{t}=g\left(W_{t}\right) W_{t} d t$, does not depend on $d K_{t}$, distributing the spending account between the current and the future investment opportunities in the way that maximizes firm value is incentive compatible. The implied amount of investment solves

$$
\max _{k \in \mathbb{R}_{+}}\left\{V(\theta, k)+P\left(\gamma\left(B_{t}-k\right)\right)\right\}
$$

which leads to

$$
\frac{\partial V(\theta, k)}{\partial k}-\gamma P^{\prime}\left(\gamma\left(B_{t}-k\right)\right)=0
$$

which gives exactly $k^{d}\left(\theta, \gamma B_{t}\right)=k^{d}\left(\theta, W_{t}\right)$.

Consider the division manager's decision to pass the project to the headquarters. If the division manager believes that the optimal investment in the project exceeds $k_{t}^{*}$, then passing the project to the headquarters is incentive compatible, because the audit will confirm the report and the project will be financed by the headquarters, which will lead to an additional utility of the division manager from private benefits. By contrast, passing the project to the headquarters if its optimal investment is below $k_{t}^{*}$ is not incentive compatible, because the division manager will be punished. It remains to show that the audit decisions implied by this mechanism are the same as the audit decisions in the mechanism in Proposition 1. Conditional on getting financed by the headquarters, the optimal level of investment in a project is $k^{a}\left(\theta, \gamma B_{t}\right)$. Because $k^{a}\left(\theta, \gamma B_{t}\right)$ is an increasing function of $\theta$ and $k_{t}^{*}=k^{a}\left(\theta^{*}\left(\gamma B_{t}\right), \gamma B_{t}\right)$, the division manager will pass the project to the headquarters if and only if $\theta \geq \theta^{*}\left(\gamma B_{t}\right)=\theta^{*}\left(W_{t}\right)$. Therefore, this mechanism implies the same audit decisions as the mechanism in Proposition 1.

Proof of Proposition 4. First, I solve for the optimal direct mechanism. Let $\left(T_{i, n}, \theta_{i, n}\right)_{n>1}$ be the process describing the occurrence of investment projects of category $i \in\{L, H\}$, where $T_{i, n}$ and $\theta_{i, n}$ denote the arrival time and the quality of the $n^{t h}$ investment project of category $i$. To continue working with a single state variable, I re-define the stochastic process $\left(d X_{t}\right)_{t \geq 0}$ describing 
the evolution of the division's investment opportunities in the following way. Let

$$
d X_{t}= \begin{cases}0, & \text { if } t \neq T_{i, n} \text { for any } n \geq 1, i \in\{L, H\} \\ \theta_{L, n}, & \text { if } t=T_{L, n} \text { for some } n \geq 1 \\ z+\theta_{H, n}, & \text { if } t=T_{H, n} \text { for some } n \geq 1\end{cases}
$$

where $z$ is any constant above $\bar{\theta}$. By analogy with Lemma 1 , the evolution of the division manager's promised utility following her report $d \hat{X}_{t}$ is

$$
\begin{aligned}
d W_{t}= & \rho W_{t-} d t-\gamma_{L} d K_{L, t}-\gamma_{H} d K_{H, t}-d C_{t} \\
& +H_{t}\left(d \hat{X}_{t}\right)-\left(\int_{\underline{\theta}}^{\bar{\theta}}\left(\lambda_{L} H_{t}(\theta)+\lambda_{H} H_{t}(z+\theta)\right) f(\theta) d \theta\right) d t,
\end{aligned}
$$

where $H_{t}\left(d \hat{X}_{t}\right)$ satisfies: (i) $H_{t}(0)=0$; (ii) for any fixed $\theta \in\{0\} \cup[\underline{\theta}, \bar{\theta}] \cup[z+\underline{\theta}, z+\bar{\theta}], H_{t}(\cdot$ ) is $F$-predictable. The extension of the model has no effect on incentive compatibility conditions for truth-telling, which are given by Lemma 2. As in Section 3.2, the optimal monetary compensation policy is described by (8). Consider region $W<W^{c}$. The same argument as in Section 3.2 leads to the following Hamilton-Jacobi-Bellman equation:

$$
\begin{aligned}
r P(W)= & \max _{\left\{k_{i, \theta}, a_{i, \theta}, h_{i, \theta}\right\}_{i \in[L, H], \theta \in \Theta}}\left\{\sum_{i \in\{L, H\}} \lambda_{i} \int_{\underline{\theta}}^{\bar{\theta}}\left(V\left(k_{i, \theta}, \theta\right)-k_{i, \theta}-c a_{i, \theta}\right) f(\theta) d \theta\right. \\
& +\left[\rho W-\sum_{i \in\{L, H\}} \lambda_{i} \int_{\underline{\theta}}^{\bar{\theta}} h_{i, \theta} f(\theta) d \theta\right] P^{\prime}(W) \\
& \left.+\sum_{i \in\{L, H\}} \lambda_{i} \int_{\underline{\theta}}^{\bar{\theta}}\left[P\left(W+h_{\theta, i}-\gamma_{i} k_{i, \theta}\right)-P(W)\right] f(\theta) d \theta\right\}
\end{aligned}
$$

where the maximization is subject to constraints $k_{i, \theta} \geq 0, a_{i, \theta} \in\{0,1\}$, and the incentive compatibility constraints $h_{i, \theta} \geq 0$, if $a_{i, \theta}=1$, and $h_{i, \theta}=0$, if $a_{i, \theta}=0$. Taking the first-order condition with respect to $h_{i, \theta}$, I obtain $h_{i, \theta}=\gamma k_{i, \theta}$, if $a_{i, \theta}=1$. Taking the first-order conditions with respect to $k_{i, \theta}$, I obtain (16) - (17), with $k_{i, \theta}$ and $\gamma_{i}$ instead of $k_{\theta}$ and $\gamma$, respectively. Let $k_{i}^{d}(\theta, W)$ and $k^{a}(\theta, W)$ denote the solutions of the former and the latter equations, respectively. Optimizing (53) with respect to $a_{i, \theta} \in\{0,1\}$ leads to $a_{i, \theta}=1$ if and only if (19) holds, with $k_{i}^{d}(\cdot)$ and $\gamma_{i}$ instead of $k^{d}(\cdot)$ and $\gamma$, respectively. By analogy with Property 4 , there exist thresholds $\theta_{i}^{*}(W), i \in\{L, H\}$, such that audit is optimal if and only if the division manager reports arrival of a project in category $i$ with quality above $\theta_{i}^{*}(W)$. To finish characterization of the optimal direct mechanism, I need to define the rate of change $g\left(W_{t}\right)$ in $W_{t}$ when $d \hat{X}_{t}=0$. Using (52), I get

$$
g(W)=\rho-\sum_{i \in\{L, H\}} \lambda_{i} \int_{\theta_{i}^{*}(W)}^{\bar{\theta}} \frac{\gamma k^{a}(\theta, W)}{W} f(\theta) d \theta .
$$

The argument for showing that the mechanism in the proposition implements the same policies as the optimal direct mechanism follows the proof of Proposition 2. The starting point is equal to $\sum_{i \in\{L, H\}} \gamma_{i} B_{i, 0}=W$ and the evolutions of $\sum_{i \in\{L, H\}} \gamma_{i} B_{i, t}$ and $W_{t}$ are the same if the investment 
policies are the same. Because the change in the division manager's utility does not depend on $d K_{t}$, allocating the spending account between the current and future investment opportunities in the way that maximizes firm value is incentive compatible. The implied investment policy is $k_{i}^{d}(\theta, W)$. Because the division manager gets extra private benefits, passing the project to the headquarters is optimal for the division manager if the optimal investment in it is above the threshold. Because the division manager gets punished, passing the project to the headquarters is suboptimal for the division manager if the optimal investment in it is below the threshold. Finally, because $k^{a}\left(\theta, \gamma B_{t}\right)$ is an increasing function of $\theta$, thresholds $k^{a}\left(\theta_{i}^{*}\left(\gamma_{L} B_{L, t}+\gamma_{H} B_{H, t}\right), \gamma_{L} B_{L, t}+\gamma_{H} B_{H, t}\right), i \in\{L, H\}$, implement the optimal audit policy.

Proof of Proposition 5. The proof is similar to that of Proposition 2. First, I show that the evolution of $W^{*}+\gamma B_{t}$ is the same as the evolution of the division manager's promised value in the optimal direct mechanism. The starting point is equal to $W^{*}+\gamma B_{0}=W_{0}$ and the change in $W^{*}+\gamma B_{t}$ if the division manager does not pass the project to the headquarters is

$$
\begin{aligned}
d\left(W^{*}+\gamma B_{t}\right) & =\gamma g^{r}\left(B_{t}\right) B_{t} d t-\gamma d K_{t} \\
& =\left(\rho-\lambda \int_{\theta^{*}\left(W^{*}+\gamma B_{t}\right)}^{\bar{\theta}} \frac{\gamma k^{a}\left(\theta, W^{*}+\gamma B_{t}\right)}{W^{*}+\gamma B_{t}} f(\theta) d \theta\right)\left(W^{*}+\gamma B_{t}\right) d t-\gamma d K_{t} .
\end{aligned}
$$

Hence, the evolutions of $W^{*}+\gamma B_{t}$ and $W_{t}$ are the same if the investment policies are the same. Because the change in the division manager's utility does not depend on $d K_{t}$, allocating the spending account between the current and future investment opportunities in the way that maximizes firm value is optimal to the division manager. The implied investment solves

$$
\max _{k \in \mathbb{R}_{+}}\left\{V(\theta, k)+P\left(W^{*}+\gamma(B-k)\right)\right\}
$$

The implied amount of investment is exactly $\hat{k}^{d}\left(\theta, W^{*}+\gamma B_{t}\right)=\hat{k}\left(\theta, W_{t}\right)$. Second, by the same argument as in the proof of Proposition 2, the division manager finds it optimal to pass the project to the headquarters if and only if the optimal amount of investment exceeds threshold $k_{t}^{*}$. Finally, because $k^{a}(\theta, W)$ is an increasing function of $\theta$, threshold $k^{a}\left(\theta^{*}\left(W^{*}+\gamma B_{t}\right), W^{*}+\gamma B_{t}\right)$ implements the optimal audit policy.

Proof of Proposition 6. Equation (31) is obtained using the argument of Section 3. The same argument as in Section 3 implies that $h_{\theta}=\gamma k_{\theta}$ in the "audit" region and $h_{\theta}=0$ in the "do not audit" region. Taking the first-order conditions of (31) with respect to $k_{\theta}$ yields equations (16) and (17), in which $P(W)$ is substituted by $P(W, t)$. Let $k^{d}(\theta, W, t)$ and $k^{a}(\theta, W, t)$ denote their solutions, respectively. Optimizing with respect to $a_{\theta}$, we obtain that $a^{*}(\theta, W, t)=1$ if and only if (19) is satisfied, in which $P(W), k^{d}(\theta, W)$, and $k^{a}(\theta, W)$ are substituted by $P(W, t), k^{d}(\theta, W, t)$, and $k^{a}(\theta, W, t)$, respectively. The proof of Property 4 also applies here and implies $a^{*}(\theta, W, t)=1$ if and only if $\theta$ is greater or equal threshold $\theta^{*}(W, t)$, defined in the same way as $\theta^{*}(W)$ in Property 4. Therefore, by analogy with Proposition 1, the optimal direct mechanism is:

1. if $d \hat{X}_{t}$ (i.e., the manager reports no arrival of a project), then $d K_{t}=0, d A_{t}=0$, and $W_{t}$ evolves according to

$$
d W_{t}=g\left(W_{t}, t\right) W_{t} d t
$$


where

$$
g\left(W_{t}, t\right)=r-\lambda \int_{\theta^{*}\left(W_{t}, t\right)}^{\bar{\theta}} \frac{\gamma k^{a}\left(\theta, W_{t}, t\right)}{W_{t}} f(\theta) d \theta
$$

2. if $d \hat{X}_{t} \in\left[\underline{\theta}, \theta^{*}\left(W_{t}, t\right)\right]$, then $d K_{t}=k^{d}\left(d \hat{X}_{t}, W_{t}, t\right), d A_{t}=0$, and $d W_{t}=-\gamma d K_{t}$;

3. if $d \hat{X}_{t} \in\left(\theta^{*}\left(W_{t}, t\right), \bar{\theta}\right]$, then $d A_{t}=1$. If the audit reveals that the report is truthful, then $d K_{t}=k^{a}\left(d \hat{X}_{t}, W_{t}, t\right)$ and $d W_{t}=0$. If the audit reveals that the report is not truthful, then $d K_{t}=0$ and $d W_{t}=-W_{t}$

4. the process of monetary transfers from the headquarters to the division manager is: $d C_{t}=0$ if $t<T$, and $d C_{T}=W_{T}$.

The argument for showing that the mechanism in the proposition implements the same policies as the optimal direct mechanism follows the proof of Proposition 2. The starting point is equal to $\gamma B_{0}=W_{0}$ and the evolutions of $\gamma B_{t}$ and $W_{t}$ are the same if the investment policies are the same. Because the change in the division manager's utility does not depend on $d K_{t}$, allocating the spending account between the current and future investment opportunities in the way that maximizes firm value is incentive compatible. The implied investment policy solves

$$
\max _{k \in \mathbb{R}_{+}}\left\{V(k, \theta)+P\left(\gamma\left(B_{t}-k\right), t\right)\right\},
$$

which gives $k^{d}\left(\theta, \gamma B_{t}, t\right)=k^{d}\left(\theta, W_{t}, t\right)$. Because the division manager gets additional private benefits, she finds it optimal to pass the project to the headquarters if the optimal investment in it is above the threshold. Because the division manager gets punished, she finds it optimal not to pass the project to the headquarters if the optimal investment in it is below the threshold. Finally, because $k^{a}(\theta, W, t)$ is an increasing function of $\theta$, threshold $k^{a}\left(\theta^{*}(W, t), W, t\right)$ implements the optimal audit policy.

\section{Appendix B: Model with Multiple Audit Technologies}

This appendix proves the following proposition:

Proposition 3. Consider the following mechanism:

1. The headquarters allocates a spending account $B_{0}$ to the division manager at the initial date and allows to use it at the manager's discretion. If $R<W^{c}$, then the size of the initial spending account is $B_{0}=\max \left\{R, W^{*}\right\} / \gamma$. If $R>W^{c}$, then an immediate payment of $R-W^{c}$ is made to the manager and $B_{0}=W^{c} / \gamma$.

2. The spending account is accumulated at the rate $g_{t}=g\left(\gamma B_{t}\right)$, if $B_{t}<B^{c}=W^{c} / \gamma$, where $g(\cdot)$ is given by (88), and is not accumulated, if $B_{t}=B^{c}$. The monetary compensation of the division manager is zero, if $B_{t}<B^{c}$, and consists of a flow of constant bonus payments $g\left(B^{c}\right) \gamma B^{c}$, if $B_{t}=B^{c}$. 
3. In addition, the headquarters specifies thresholds $k_{t}^{*}$ and $k_{t}^{* *} \geq k_{t}^{*}$, given by

$$
\begin{aligned}
k_{t}^{*} & =k^{s a}\left(\theta^{*}\left(\gamma B_{t}\right), \gamma B_{t}\right), \\
k_{t}^{* *} & =k^{s a}\left(\theta^{* *}\left(\gamma B_{t}\right), \gamma B_{t}\right),
\end{aligned}
$$

where $k^{s a}(\cdot, \cdot)$ is given by (78). At any time $t \geq 0$ the division manager has an option to pass the project to the headquarters claiming that it deserves the investment $k \geq k_{t}^{*}$.

4. If the division manager claims that the project deserves the investment $k>k_{t}^{* *}$, then the project is audited using technology 2. If the audit confirms that the project deserves the reported amount, the project gets financed fully by the headquarters. If the audit does not confirm that the project deserves the reported amount, the division manager is punished.

5. If the division manager claims that the project deserves the investment $k \in\left[k_{t}^{*}, k_{t}^{* *}\right)$, then the project is audited using technology 1.

(a) If the audit is successful, then: (i) if it confirms that the project deserves the reported amount, the project gets financed fully by the headquarters; (ii) if it does not confirm that the project deserves the reported amount, the division manager is punished.

(b) If the audit is unsuccessful, then: (i) if the reported amount of investment is below $k_{t}^{* * *}=B_{t} /(1-p)$, then the project gets financed fully by the headquarters; (ii) if the reported amount of investment is above $k_{t}^{* * *}$, then the headquarters finances $k_{t}^{* * *}$ and the division manager finances the rest out of her spending account.

This mechanism is optimal.

First, I solve for the optimal direct mechanism. Second, I show that the mechanism in Proposition 3 implements the same policies.

Let $s_{t} \in\{0,1\}$ denote the success of the audit at time $t$. If the headquarters audits the report using technology 2 , then $s_{t}=1$ with probability 1 . If the headquarters audits the report using technology 1 , then $s_{t}=1$ with probability $p$. If the report is not audited, then $s_{t}=0$ with probability 1. By analogy with Lemma 1, I can write the evolution of the division manager's promised utility to her report $d \hat{X}_{t}$ as

$$
d W_{t}=\rho W_{t-} d t-\gamma d K_{t}-d C_{t}+H_{t}\left(d \hat{X}_{t}, s_{t}\right)-\lambda \mathbb{E}_{\theta, s}\left[H_{t}(\theta, s)\right] d t,
$$

where $H_{t}\left(d \hat{X}_{t}, 0\right)$ is the sensitivity of the division manager's utility to her report when audit is not successful and $H_{t}\left(d \hat{X}_{t}, 1\right)$ is the sensitivity of the division manager's utility to her report when audit is successful and confirms the division manager's report. As before, a standard argument implies that if audit reveals that the division manager has lied, then it is optimal to decrease the division manager's utility to zero: $d W_{t}=-W_{t}$.

Let $D_{t}^{A 1}=\left\{d \hat{X}_{t} \mid d A_{t}=1\right\}, D_{t}^{A 2}=\left\{d \hat{X}_{t} \mid d A_{t}=2\right\}$, and $D_{t}^{D}=\left\{d \hat{X}_{t} \mid d A_{t}=0\right\}$ be the "audit using technology 1," "audit using technology 2," and "do not audit" regions of reports at time $t$, respectively. Because $c_{1}>0,\{0\} \in D_{t}^{D}$. By analogy with Lemma 2, truth-telling is incentive compatible if and only if $H_{t}\left(d \hat{X}_{t}, 0\right)$ and $H_{t}\left(d \hat{X}_{t}, 1\right)$ satisfy the following restrictions: 
Lemma 3. For any time $t \geq 0$, truth-telling is incentive compatible if and only if:

(a) $\forall d \hat{X}_{t} \in D_{t}^{D}: H_{t}\left(d \hat{X}_{t}, 0\right)=0$;

(b) $\forall d X_{t} \in D_{t}^{A 1}: p H_{t}\left(d \hat{X}_{t}, 1\right)+(1-p) H_{t}\left(d \hat{X}_{t}, 0\right) \geq 0$ and $(1-p) H_{t}\left(d \hat{X}_{t}, 0\right) \leq p W_{t}$;

(c) $\forall d X_{t} \in D_{t}^{A 2}: H_{t}\left(d \hat{X}_{t}, 1\right) \geq 0$.

Proof. Consider any $d X_{t} \in D_{t}^{D}$. Report $d X_{t}$ dominates any report $d \hat{X}_{t} \in D_{t}^{A 2}$, because lying will be exposed and the division manager's expected future utility will drop to zero. Report $d X_{t}$ dominates report $d \hat{X}_{t} \in D_{t}^{A 1}$ if and only if

$$
H_{t}\left(d X_{t}, 0\right) \geq-p W_{t}+(1-p) H_{t}\left(d \hat{X}_{t}, 0\right) .
$$

In (63), the left-hand side is the change in the division manager's utility following a truthful report $d X_{t}$, while the right-hand side is the change in the division manager's utility following report $d \hat{X}_{t} \in$ $D_{t}^{A 1}$. With probability $p$, audit is successful. In this case, lying will be exposed and the division manager's promised utility will drop to zero. With probability $1-p$, audit is not successful. In this case, lying will not be exposed and the division manager's utility will change by $H_{t}\left(d \hat{X}_{t}, 0\right)$. Finally, report $d X_{t}$ dominates any report $d \hat{X}_{t} \in D_{t}^{D}, d \hat{X}_{t} \neq d X_{t}$ if and only if $H_{t}\left(d X_{t}, 0\right) \geq H\left(d \hat{X}_{t}, 0\right)$. Because this inequality must hold for any $d X_{t}, d \hat{X}_{t} \in D_{t}^{D}$ and $H_{t}(0,0)=0$, truth-telling is incentive compatible for all $d X_{t} \in D_{t}^{D}$ if and only if

$$
\begin{aligned}
H_{t}\left(d X_{t}, 0\right) & =0 \forall d X_{t} \in D_{t}^{D} \\
0 & \geq-p W_{t}+(1-p) H_{t}\left(d \hat{X}_{t}, 0\right) \quad \forall d \hat{X}_{t} \in D_{t}^{A 1}
\end{aligned}
$$

where the second inequality follows from (63) - (64).

Consider any $d X_{t} \in D_{t}^{A 1}$. Again, report $d X_{t}$ dominates any report $d \hat{X}_{t} \in D_{t}^{A 2}$, because lying will be exposed and the division manager's expected future utility will drop to zero. By analogy with (63), report $d X_{t}$ dominates report $d \hat{X}_{t} \in D_{t}^{A 1}, d \hat{X}_{t} \neq d X_{t}$ if and only if

$$
p H_{t}\left(d X_{t}, 1\right)+(1-p) H_{t}\left(d X_{t}, 0\right) \geq-p W_{t}+(1-p) H_{t}\left(d \hat{X}_{t}, 0\right) .
$$

Finally, report $d X_{t}$ dominates report $d \hat{X}_{t} \in D_{t}^{D}$ if and only if

$$
p H_{t}\left(d X_{t}, 1\right)+(1-p) H_{t}\left(d X_{t}, 0\right) \geq H_{t}\left(d \hat{X}_{t}, 0\right)=0,
$$

Notice that constraint (66) is implied by conditions (65) and (67). Therefore, truth-telling is incentive compatible for all $d X_{t} \in D_{t}^{A 1}$ if and only if (67) is satisfied for all $d X_{t} \in D_{t}^{A 1}$.

Consider any $d X_{t} \in D_{t}^{A 2}$. Again, report $d X_{t}$ dominates any report $d \hat{X}_{t} \in D_{t}^{A 2}, d \hat{X}_{t} \neq d X_{t}$, because lying will be exposed and the division manager's expected future utility will drop to zero. By analogy with (63) and (66), report $d X_{t}$ dominates report $d \hat{X}_{t} \in D_{t}^{A 1}$ if and only if

$$
H_{t}\left(d X_{t}, 1\right) \geq-p W_{t}+(1-p) H_{t}\left(d \hat{X}_{t}, 0\right) .
$$


Finally, report $d X_{t}$ dominates report $d \hat{X}_{t} \in D_{t}^{D}$ if and only if

$$
H_{t}\left(d X_{t}, 1\right) \geq H\left(d \hat{X}_{t}, 0\right)=0
$$

Constraint (68) is implied by constraints (65) and (69). Therefore, truth-telling is incentive compatible for all $d X_{t} \in D_{t}^{A 2}$ if and only if (69) is satisfied for all $d X_{t} \in D_{t}^{A 2}$.

Combining the three cases yields the conditions in the lemma.

Given the results in Lemma 3, I can solve for the optimal direct mechanism using the dynamic programming approach. As in Section 3.2, the optimal monetary compensation policy is described by (8). Consider region $W<W^{c}$. The same argument as in Section 3.2 leads to the following Hamilton-Jacobi-Bellman equation:

$$
\begin{aligned}
r P(W)= & \max _{\left\{a_{\theta}, k_{\theta}^{1}, k_{\theta}^{0}, h_{\theta}^{1}, h_{\theta}^{0}\right\}_{\theta \in \Theta}}\left\{\lambda \int_{\underline{\theta}}^{\bar{\theta}}\left(V\left(k_{\theta}, \theta\right)-k_{\theta}-c_{1} 1_{\left\{a_{\theta}=1\right\}}-c_{2} 1_{\left\{a_{\theta}=2\right\}}\right) f(\theta) d \theta\right. \\
& +\left[\rho W-\lambda \int_{\underline{\theta}}^{\bar{\theta}}\left[h_{\theta}^{0}\left(1_{\left\{a_{\theta}=0\right\}}+(1-p) 1_{\left\{a_{\theta}=1\right\}}\right)+h_{\theta}^{1}\left(p 1_{\left\{a_{\theta}=1\right\}}+1_{\left\{a_{\theta}=2\right\}}\right)\right] f(\theta) d \theta\right] P^{\prime}(W) \\
& +\lambda \int_{\underline{\theta}}^{\bar{\theta}}\left[P\left(W+h_{\theta}^{0}-\gamma k_{\theta}^{0}\right)\left(1_{\left\{a_{\theta}=0\right\}}+(1-p) 1_{\left\{a_{\theta}=1\right\}}\right)\right. \\
& \left.\left.+P\left(W+h_{\theta}^{1}-\gamma k_{\theta}^{1}\right)\left(p 1_{\left\{a_{\theta}=1\right\}}+1_{\left\{a_{\theta}=2\right\}}\right)-P(W)\right] f(\theta) d \theta\right\},
\end{aligned}
$$

where the maximization is subject to constraints $a_{\theta} \in\{0,1,2\}, k_{\theta}^{1} \geq 0, k_{\theta}^{0} \geq 0$, and the incentive compatibility constraints

$$
\begin{aligned}
h_{\theta}^{0} & =0, \text { if } a_{\theta}=0 \\
p h_{\theta}^{1}+(1-p) h_{\theta}^{0} & \geq 0, \text { if } a_{\theta}=1 \\
(1-p) h_{\theta}^{0} & \leq W, \text { if } a_{\theta}=1 \\
h_{\theta}^{1} & \geq 0, \text { if } a_{\theta}=2 .
\end{aligned}
$$

Taking the derivative of $(12)$ with respect to $h_{\theta}^{i}$ yields

$$
-P^{\prime}(W)+P^{\prime}\left(W+h_{\theta}^{i}-\gamma k_{\theta}^{i}\right) .
$$

Then, $h_{\theta}^{1}=\gamma k_{\theta}^{1}$. In the "audit using technology 1 " range, $h_{\theta}^{0}=\gamma k_{\theta}^{0}$ if constraint (73) is lax and $h_{\theta}^{0}=W /(1-p)$ if constraint (73) is binding. Thus, $h_{\theta}^{0}=\min \left\{W /(1-p), \gamma k_{\theta}^{0}\right\}$.

This proves the following lemma, which is the analogue of Property 2 in Section 3.2:

Lemma 4. Under the optimal mechanism, the evolution of the division manager's promised utility following a report of project $\theta$ is as follows:

(a) if the report is not audited, then the division manager's promised value is reduced by the amount $\gamma k_{\theta}$ of private benefits from the project;

(b) if the report is audited and confirmed to be truthful, then the division manager's promised value is unaffected; 
(c) if the report is audited and turns out to be non-truthful, then the division manager's promised value is reduced to zero;

(d) if the report is audited using technology 1 and audit is unsuccessful, then the division manager's promised value is reduced by $\max \left\{\gamma k_{\theta}-W /(1-p), 0\right\}$.

Using this result, I solve for the optimal investment. Taking the first derivative of (12) with respect to $k_{\theta}$ yields:

$$
\begin{aligned}
\frac{\partial V\left(k_{\theta}, \theta\right)}{\partial \theta}-1-\gamma P^{\prime}\left(W-\gamma k_{\theta}\right) & =0, \text { if } a_{\theta}=0 \\
\frac{\partial V\left(k_{\theta}, \theta\right)}{\partial \theta}-1-\gamma P^{\prime}\left(\min \left\{W \frac{2-p}{1-p}-\gamma k_{\theta}, W\right\}\right) & =0, \text { if } a_{\theta}=1, s_{t}=0 \\
\frac{\partial V\left(k_{\theta}, \theta\right)}{\partial \theta}-1-\gamma P^{\prime}(W) & =0, \text { if } a_{\theta}=1, s_{t}=1 \text { or } a_{\theta}=2,
\end{aligned}
$$

Let $k^{d}(\theta, W), k^{u a}(\theta, W)$, and $k^{s a}(\theta, W)$ denote the solutions of (76), (77), and (78), respectively. By concavity of $P(W), k^{d}(\theta, W)<k^{u a}(\theta, W) \leq k^{s a}(\theta, W)$ with the latter inequality being strict in the range in which (73) is binding.

Finally, it remains to solve for the optimal audit strategies. This is done in the next lemma, which is the analogue of Property 4 in Section 3.2:

Lemma 5. There exist points $\theta^{*}(W) \in \Theta$ and $\theta^{* *}(W) \in \Theta, \theta^{* *}(W)>\theta^{*}(W)$, defined below, such that the optimal audit strategy is

$$
a^{*}(\theta, W)= \begin{cases}0, & \text { if } \theta \leq \theta^{*}(W) \\ 1, & \text { if } \theta \in\left(\theta^{*}(W), \theta^{* *}(W)\right), \\ 2, & \text { if } \theta \geq \theta^{* *}(W)\end{cases}
$$

Proof. Let

$$
\begin{aligned}
F^{s a}(\theta, W)= & \max _{k \in \mathbb{R}_{+}}\left\{V(k, \theta)-k+P(W)-\gamma k P^{\prime}(W)\right\}, \\
F^{u a}(\theta, W)= & \max _{k \in \mathbb{R}_{+}}\left\{V(k, \theta)-k+P\left(\min \left\{W \frac{2-p}{1-p}-\gamma k, W\right\}\right)\right. \\
& \left.-\min \left\{\gamma k, \frac{\gamma W}{1-p}\right\} P^{\prime}(W)\right\}, \\
F^{d}(\theta, W)= & \max _{k \in \mathbb{R}_{+}}\{V(k, \theta)-k+P(W-\gamma k)-P(W)\} .
\end{aligned}
$$

Strategy "audit using technology 1" is better than strategy "do not audit" if and only if

$$
p F^{a}(\theta, W)+(1-p) F^{u a}(\theta, W)-F^{d}(\theta, W) \geq c_{1} .
$$


By the envelope theorem, the derivative of the left-hand side with respect to $\theta$ is

$$
\begin{aligned}
& p \frac{\partial V\left(k^{s a}(\theta, W), \theta\right)}{\partial \theta}+(1-p) \frac{\partial V\left(k^{u a}(\theta, W), \theta\right)}{\partial \theta}-\frac{\partial V\left(k^{d}(\theta, W), \theta\right)}{\partial \theta} \\
= & p \int_{k^{d}(\theta, W)}^{k^{s a}(\theta, W)} \frac{\partial^{2} V(k, \theta)}{\partial k \partial \theta} d k+(1-p) \int_{k^{d}(\theta, W)}^{k^{u a}(\theta, W)} \frac{\partial^{2} V(k, \theta)}{\partial k \partial \theta} d k>0,
\end{aligned}
$$

because $k^{s a}(\theta, W)>k^{d}(\theta, W), k^{u a}(\theta, W)>k^{d}(\theta, W)$, and $\partial^{2} V(k, \theta) / \partial k \partial \theta>0$ by Assumption 1 . Therefore, the left-hand side of (83) is an increasing function of $\theta$. Let $\theta_{1}(W) \in \Theta$ denote the point at which (83) holds as equality, if it exists. If the left-hand side of (83) is below $c_{1}$ for all $\theta \in \Theta$, let $\theta_{1}(W)$ be any point above $\bar{\theta}$. If the left-hand side of (83) is above $c_{1}$ for all $\theta \in \Theta$, let $\theta_{1}(W)$ be any point below $\underline{\theta}$.

Strategy "audit using technology 2" is better than strategy "audit using technology 1" if and only if

$$
(1-p)\left(F^{s a}(\theta, W)-F^{u a}(\theta, W)\right) \geq c_{2}-c_{1} .
$$

By the envelope theorem, the derivative of the left-hand side with respect to $\theta$ has the same sign as

$$
\begin{aligned}
& \frac{\partial V\left(k^{s a}(\theta, W), \theta\right)}{\partial \theta}-\frac{\partial V\left(k^{u a}(\theta, W), \theta\right)}{\partial \theta} \\
= & \int_{k^{u a}(\theta, W)}^{k^{s a}(\theta, W)} \frac{\partial^{2} V(k, \theta)}{\partial k \partial \theta} d k \geq 0,
\end{aligned}
$$

and strictly positive if constraint (73) is binding. Because $k^{u a}(\theta, W)$ is an increasing function of $\theta$, if (73) is binding for $\tilde{\theta}$, it is binding for all $\theta>\tilde{\theta}$. Moreover, in the range of $\theta$ in which (73) is binding, the left-hand side of (85) is zero. Therefore, there exists at most one point at which (85) holds as equality, and (85) holds as a strict inequality if and only if $\theta$ is above this point. Let $\theta_{2}(W) \in \Theta$ denote the point at which (85) holds as equality, if it exists. If the left-hand side of (85) is below $c_{2}-c_{1}$ for all $\theta \in \Theta$, let $\theta_{2}(W)$ be any point above $\bar{\theta}$. If the left-hand side of (85) is above $c_{2}-c_{1}$ for all $\theta \in \Theta$, let $\theta_{2}(W)$ be any point below $\underline{\theta}$.

Finally, let $\theta^{*}(W)=\min \left\{\theta_{1}(W), \theta_{2}(W)\right\}$. Then, in the range $\theta \leq \theta^{*}(W)$ strategy "do not audit" is more optimal than strategies "audit using technology 1" and "audit using technology 2." If $\theta_{2}(W)>\theta_{1}(W)$, then let $\theta^{* *}(W)=\theta_{2}(W)$. Then, in the range $\theta \in\left(\theta^{*}(W), \theta^{* *}(W)\right]$ strategy "audit using technology 1 " is better than strategy "do not audit" by the argument in the first paragraph and than strategy "audit using technology 2," because it is dominated by strategy "do not audit" by the argument in the second paragraph. Similarly, in the range $\theta>\theta^{* *}(W)$ strategy "audit using technology 2" is better than strategy "audit using technology 1 " by the argument in the second paragraph and than strategy "do not audit," because it is dominated by strategy "audit using technology 1" by the argument in the first paragraph. If $\theta_{1}(W)>\theta_{2}(W)$, let $\theta^{* *}(W)=$ $\theta^{*}(W)=\theta_{2}(W)$. Then, in the range $\theta>\theta^{* *}(W)=\theta^{*}(W)$ strategy "audit using technology 2" is better than strategy "audit using technology 1" by the argument in the second paragraph and than strategy "do not audit," because it is dominated by strategy "audit using technology 1" by the argument in the first paragraph.

To finish characterization of the optimal direct mechanism, I need to define the evolution of $W_{t}$ when $d \hat{X}_{t}=0$. Using (62), I get

$$
d W_{t}=g\left(W_{t}\right) W_{t} d t
$$


where

$$
\begin{aligned}
g(W)= & \rho-\lambda \int_{\theta^{*}(W)}^{\bar{\theta}} \frac{\gamma k^{s a}(\theta, W)}{W} f(\theta) d \theta \\
& +\lambda \int_{\theta^{*}(W)}^{\theta^{* *}(W)} \frac{\gamma(1-p)\left(k^{s a}(\theta, W)-k^{u a}(\theta, W)\right)}{W} f(\theta) d \theta
\end{aligned}
$$

Next, I show that at any time $t$ the mechanism in Proposition 3 leads to the same investment, audit, monetary compensation policies, and evolution of the division manager's expected future utility as the optimal direct mechanism. First, using the argument of Proposition 2, it is easy to show that the evolution of $\gamma B_{t}$ is the same as the evolution of $W_{t}$ in the optimal direct mechanism. The starting point is equal to $\gamma B_{0}=W_{0}$ and the increments of $\gamma B_{t}$ and $W_{t}$ are the same if the investment policies are the same. Because in the "do not audit region" the change in the division manager's utility does not depend on $d K_{t}$, allocating the spending account between the current and future investment opportunities in the way that maximizes firm value is incentive compatible. The implied investment policy is $k^{d}\left(\theta, \gamma B_{t}\right)=k^{d}\left(\theta, W_{t}\right)$. Similarly, consider the "audit using technology 1 " region and suppose that audit is unsuccessful. If the headquarters provides only $k_{t}^{* * *}$ of capital, then the additional investment of the division manager does not affect her utility. Hence, the division manager has incentives to co-finance the project in a way that maximizes firm value. The implied investment policy is $k^{u a}(\theta, W)$. The same argument as in Proposition 2 applies here to show that the division manager has incentives to pass the project to the headquarters and state the optimal investment truthfully. 


\section{References}

[1] Akalu, Mehari Mekonnen, 2003, The process of investment appraisal: the experience of 10 large British and Dutch companies, International Journal of Project Management 21, 355-362.

[2] Albuquerque, Rui, and Hugo A. Hopenhayn, 2004, Optimal lending contracts and firm dynamics, Review of Economic Studies 71, 285-315.

[3] Alonso, Ricardo, and Niko Matouschek, 2007, Relational delegation, RAND Journal of Economics 38, 1070-1089.

[4] Alonso, Ricardo, and Niko Matouschek, 2008, Optimal delegation, Review of Economic Studies 75, 259-293.

[5] Antle, Rick, and Gary D. Eppen, 1985, Capital rationing and organizational slack in capital budgeting, Management Science 31, 163-174.

[6] Berkovitch, Elazar, and Ronen Israel, 2004, Why the NPV criterion does not maximize NPV, Review of Financial Studies 17, 239-255.

[7] Bernardo, Antonio E., Hongbin Cai, and Jiang Luo, 2001, Capital budgeting and compensation with asymmetric information and moral hazard, Journal of Financial Economics 61, 311-344.

[8] Bernardo, Antonio E., Hongbin Cai, and Jiang Luo, 2004, Capital budgeting in multidivision firms: information, agency, and incentives, Review of Financial Studies 17, 739-767.

[9] Bernardo, Antonio E., Jiang Luo, and James J.D. Wang, 2006, A theory of socialistic internal capital markets, Journal of Financial Economics 80, 485-509.

[10] Biais, Bruno, Thomas Mariotti, Guillaume Plantin, and Jean-Charles Rochet, 2007, Dynamic security design: convergence to continuous time and asset pricing implications, Review of Economic Studies 74, 345-390.

[11] Biais, Bruno, Thomas Mariotti, Jean-Charles Rochet, and Stéphane Villeneuve, 2010, Large risks, limited liability, and dynamic moral hazard, Econometrica 78, 73-118.

[12] Bloom, Nicholas, Benn Eifert, Aprajit Mahajan, David McKenzie, and John Roberts, 2010, Does management matter? Evidence from India, Working Paper.

[13] Clementi, Gian Luca, and Hugo A. Hopenhayn, 2006, A theory of financing constraints and firm dynamics, Quarterly Journal of Economics 121, 229-265.

[14] DeMarzo, Peter M., and Michael J. Fishman, 2007a, Agency and optimal investment dynamics, Review of Financial Studies 20, 151-188.

[15] DeMarzo, Peter M., and Michael J. Fishman, 2007b, Optimal long-term financial contracting, Review of Financial Studies 20, 2079-2128.

[16] DeMarzo, Peter M., Michael J. Fishman, Zhiguo He, and Neng Wang, 2009, Dynamic agency and the q theory of investment, Working Paper.

[17] DeMarzo, Peter M., and Yuliy Sannikov, 2006, Optimal security design and dynamic capital structure in a continuous-time agency model, Journal of Finance 61, 2681-2724. 
[18] Dessein, Wouter, 2002, Authority and communication in organizations, Review of Economic Studies 69, 811-838.

[19] Gale, Douglas, and Martin Hellwig, 1985, Incentive-compatible debt contracts: the one-period problem, Review of Economic Studies 52, 647-663.

[20] Gertner, Robert H., David S. Scharfstein, and Jeremy C. Stein, 1994, Internal versus external capital markets, Quarterly Journal of Economics 109, 1211-1230.

[21] Gitman, Lawrence T., and John R. Forrester, 1977, A survey of capital budgeting techniques used by major U.S. firms, Financial Management 6, 66-71.

[22] Graham, John R., Campbell R. Harvey, and Manju Puri, 2010, Capital allocation and delegation of decision-making authority within firms, Working Paper.

[23] Green, Edward, 1987, Lending and smoothing of uninsurable income, in Edward Prescott and Neil Wallace, ed.: Contractual Arrangements for Intertemporal Trade (University of Minnesota Press, Minneapolis, MN).

[24] Harris, Milton, Charles H. Kriebel, and Artur Raviv, 1982, Asymmetric information, incentives and intrafirm resource allocation, Management Science 28, 604-620.

[25] Harris, Milton, and Artur Raviv, 1996, The capital budgeting process: Incentives and information, Journal of Finance 46, 297-355.

[26] Harris, Milton, and Artur Raviv, 1998, Capital budgeting and delegation, Journal of Financial Economics 50, 259-289.

[27] Harris, Milton, and Artur Raviv, 2005, Allocation of decision-making authority, Review of Finance 9, 353-383.

[28] Holmstrom, Bengt, and Joan Ricart i Costa, 1986, Managerial incentives and capital management, Quarterly Journal of Economics 101, 835-860.

[29] Inderst, Roman, and Holger M. Müller, 2003, Internal versus external financing: an optimal contracting approach, Journal of Finance 58, 1033-1062.

[30] Last, Günter, and Andreas Brandt, 1995. Marked Point Processes on the Real Line: The Dynamic Approach (Springer-Verlag, New York).

[31] Marino, Anthony M., and John G. Matsusaka, 2005, Decision processes, agency problems, and information: an economic analysis of capital budgeting procedures, Review of Financial Studies $18,301-325$.

[32] Mathews, Richmond D., and David T. Robinson, 2008, Market structure, internal capital markets, and the boundaries of the firm, Journal of Finance 63, 2703-2736.

[33] Matsusaka, John G., and Vikram Nanda, 2002, Internal capital markets and corporate refocusing, Journal of Financial Intermediation 11, 176-211.

[34] Mookherjee, Dilip, and Stefan Reichelstein, 1997, Budgeting and hierarchical control, Journal of Accounting Research 35, 129-155. 
[35] Petty, J. William, David F. Scott, and Monroe M. Bird, 1975, The capital expenditure decisionmaking process of large corporations, Engineering Economist 20, 159-172.

[36] Piskorski, Tomasz, and Alexei Tchistyi, 2010, Optimal mortgage design, Review of Financial Studies 23, 3098-3140.

[37] Piskorski, Tomasz, and Mark M. Westerfield, 2010, Optimal financing in the presence of monitoring: debt contracts and recapitalization in distress, Working Paper.

[38] Quadrini, Vincenzo, 2004, Investment and liquidation in renegotiation-proof contracts with moral hazard, Journal of Monetary Economics 51, 713-751.

[39] Ross, Marc, 1986, Capital budgeting practices of twelve large manufacturers, Financial Management 15, 15-22.

[40] Ryan, Patricia A., and Glenn P. Ryan, 2002, Capital budgeting practices of the Fortune 1000: how have things changed, Journal of Business and Management 8, 355-364.

[41] Sannikov, Yuliy, 2008, A continuous-time version of the principal-agent problem, Review of Economic Studies 75, 957-984.

[42] Shreve, Steven E., 2004, Stochastic Calculus for Finance II: Continuous-Time Models (SpringerVerlag, New York, NY).

[43] Slagmulder, Regine, Werner Bruggeman, and Luk van Wassenhove, 1995, An empirical study of capital budgeting practices for strategic investments in CIM technologies, International Journal of Production Economics 40, 121-152.

[44] Spear, Stephen E., and Sanjay Srivastava, 1987, On repeated moral hazard with discounting, Review of Economic Studies 54, 599-617.

[45] Stein, Jeremy C., 2003, Agency, information and corporate investment, in: George M. Constantinides, René M. Stulz, and Milton Harris, ed.: Handbook of the Economics of Finance, Vol. 1, Part 1, 111-165.

[46] Tchistyi, Alexei, 2006, Security design with correlated hidden cash flows: The optimality of performance pricing, Working Paper.

[47] Thomas, Jonathan, and Tim Worrall, 1988, Self-enforcing wage contracts, Review of Economic Studies 55, 541-553.

[48] Townsend, Robert M., 1979, Optimal contracts and competitive markets with costly state verification, Journal of Economic Theory 21, 265-293. 


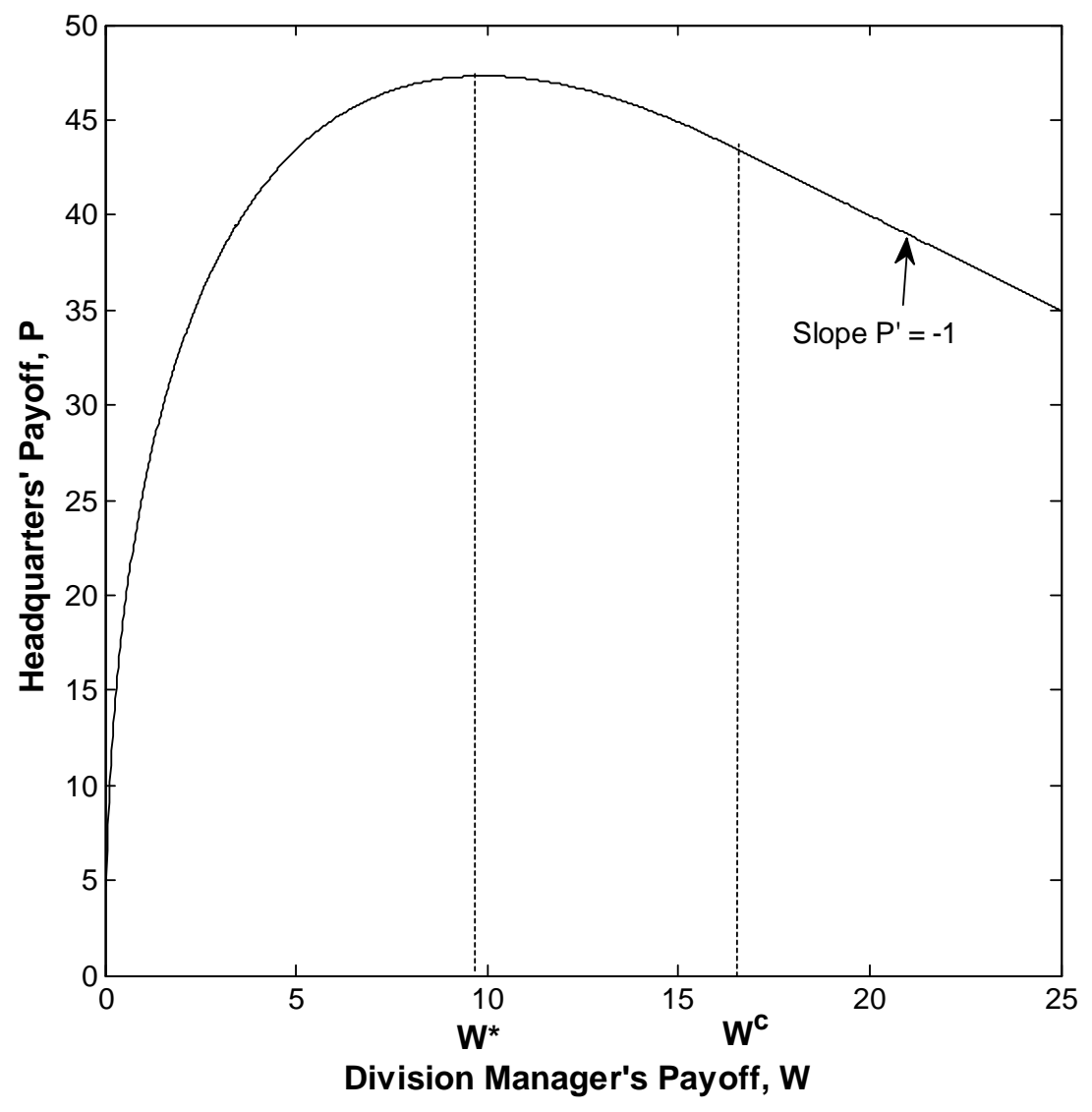

Figure 2. The headquarters' value function $\mathbf{P}(\mathbf{W})$. The figure shows the headquarters' value under the optimal mechanism as a function of the division manager's expected future payoff W. Point $W^{\star}$ is the one at which $\mathrm{P}(\mathrm{W})$ is maximized. When the manager's promised utility reaches $W^{c}$, the headquarters' value function continues with slope -1 . In this and the subsequent figures, unless stated otherwise, the parameter values are $\mathrm{r}=0.1, \rho=0.12, \lambda=4, \gamma=0.25, \mathrm{c}=0.05, V(\theta, k)=A \theta \sqrt{k}$ with $\mathrm{A}=10, \theta$ has power distribution over $[0,1]$ with parameter 0.1 . 

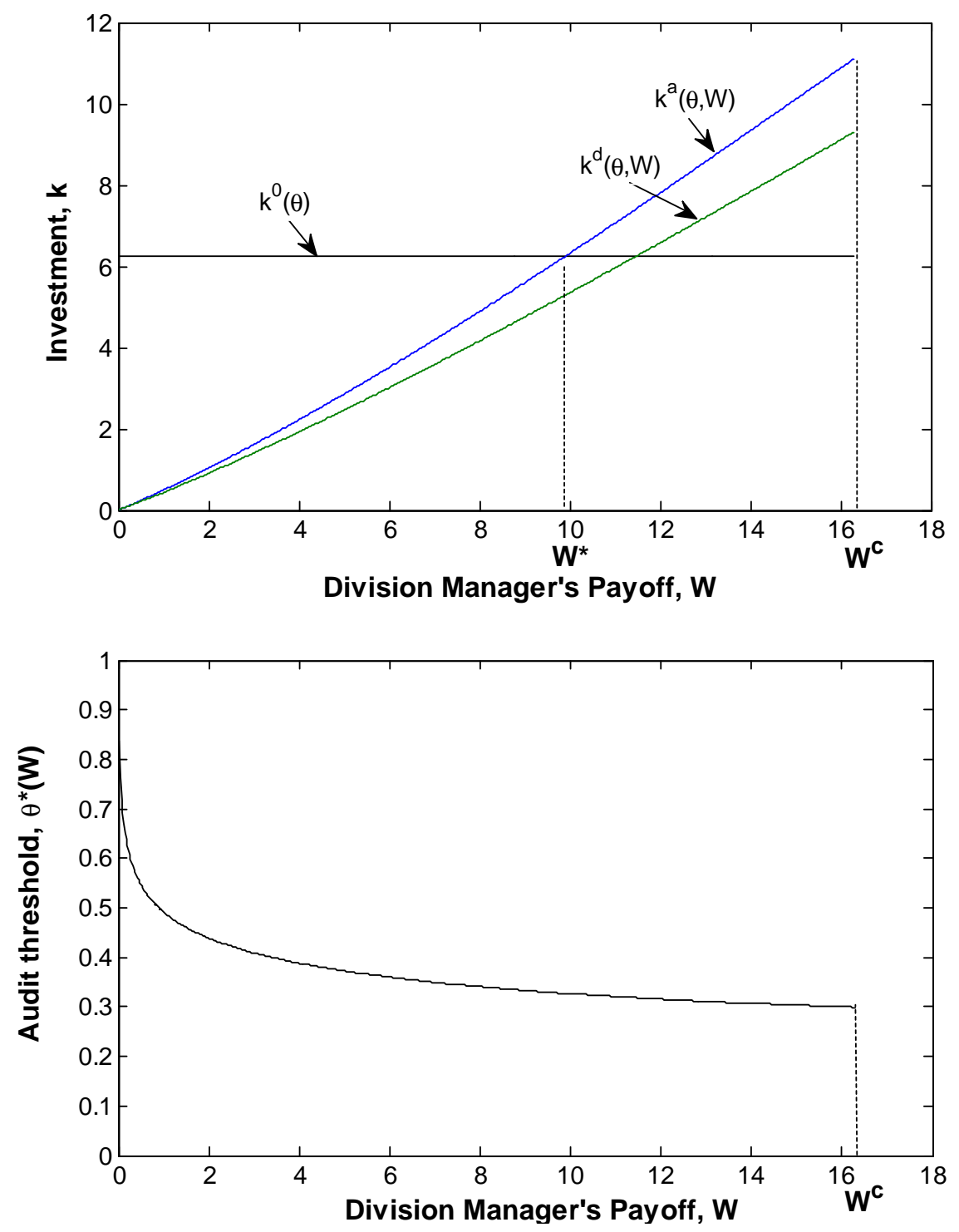

Figure 3. Audit threshold and investment under the optimal mechanism. The top figure plots the optimal investment for a project with quality $\theta=0.5$ as a function of the division manager's payoff $W$. The constant (black) line corresponds to the NPV-maximizing level of investment, $k^{0}(\theta)$. The upper increasing (blue) line corresponds to the optimal investment conditional on the project being audited, $k^{a}(\theta, W)$. The lower increasing (green) line corresponds to the optimal investment conditional on the project not being audited, $k^{d}(\theta, W)$. The bottom figure plots the optimal audit threshold $\theta^{\star}(W)$ as a function of the division manager's payoff $W$. For any $W$, the headquarters audits the division manager's report if and only if the division manager reports arrival of a project with quality above $\theta^{\star}(W)$. 


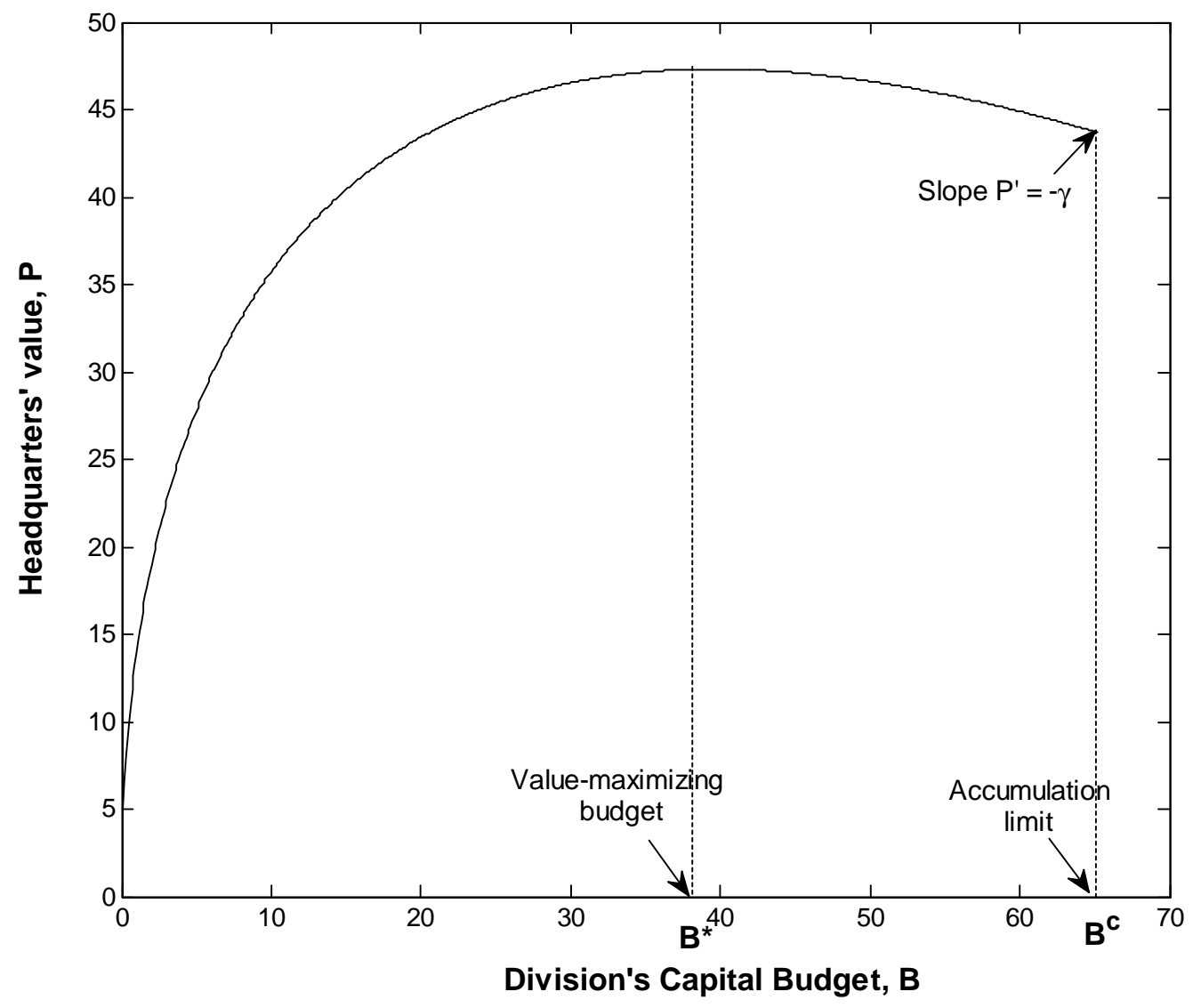

Figure 4. The headquarters' value function in the budgeting mechanism. The figure shows the headquarters' value as a function of the division manager's spending account balance (i.e., current capital budget), B. Point $B^{\star}$ corresponds to account balance at which the headquarters' value is maximized. This point corresponds to the size of the initial allocated budget when $\mathrm{R}$ is low enough. Point $B^{c}$ is the accumulation limit of the spending account. At this point, the headquarters' value function has the slope of $-\gamma$. Once the division manager's spending account balance reaches $B^{c}$, the division manager receives a flow of constant monetary payments. 

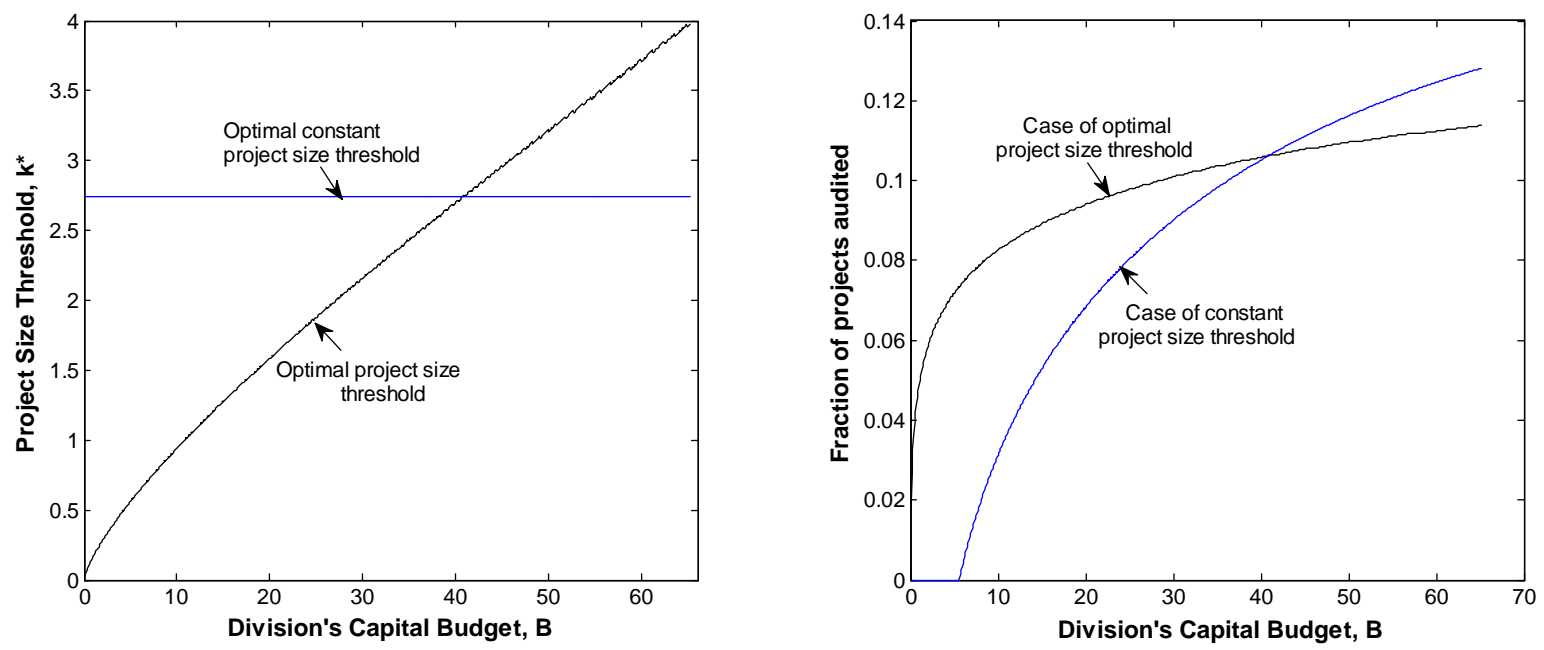

Figure 5. Division of authority in the optimal mechanism. The left figure shows the optimal threshold on the size of individual projects as a function of the division manager's spending account balance (i.e., current capital budget), B, (in black) and the optimal threshold in the constrained optimal mechanism, in which the threshold is required to be fixed (in blue). All projects with investment below the threshold are delegated to the division manager and are financed out of the division manager's account, while all projects with investment above the threshold are passed to the headquarters and are fully financed by the headquarters. The right figure shows the corresponding proportions of investment projects that the division manager passes to the headquarters. 